NBER WORKING PAPER SERIES

\title{
THE INS AND OUTS OF CYCLICAL UNEMPLOYMENT
}

\author{
Michael W. Elsby \\ Ryan Michaels \\ Gary Solon \\ Working Paper 12853 \\ http://www.nber.org/papers/w12853
NATIONAL BUREAU OF ECONOMIC RESEARCH
1050 Massachusetts Avenue
Cambridge, MA 02138 \\ January 2007
}

The authors are grateful for comments from seminar participants at an NBER Monetary Economics conference, the University of Michigan, York University, and the CEPR European Summer Symposium in Labor Economics. The views expressed herein are those of the author(s) and do not necessarily reflect the views of the National Bureau of Economic Research.

(C) 2007 by Michael W. Elsby, Ryan Michaels, and Gary Solon. All rights reserved. Short sections of text, not to exceed two paragraphs, may be quoted without explicit permission provided that full credit, including $(\mathrm{C}$ notice, is given to the source. 
The Ins and Outs of Cyclical Unemployment

Michael W. Elsby, Ryan Michaels, and Gary Solon

NBER Working Paper No. 12853

January 2007

JEL No. E24,E32,J63,J64

\begin{abstract}
$\underline{\text { ABSTRACT }}$
One of the strongest trends in recent macroeconomic modeling of labor market fluctuations is to treat unemployment inflows as acyclical. This trend stems in large part from an influential paper by Shimer on "Reassessing the Ins and Outs of Unemployment," i.e., the extent to which increased unemployment during a recession arises from an increase in the number of unemployment spells versus an increase in their duration. After broadly reviewing the previous literature, we replicate and extend Shimer's main analysis. Like Shimer, we find an important role for increased duration. But contrary to Shimer's conclusions, we find that even his own methods and data, when viewed in an appropriate metric, reveal an important role for increased inflows to unemployment as well. This finding is further strengthened by our refinements of Shimer's methods of correcting for data problems and by our detailed examination of particular components of the inflow to unemployment. We conclude that a complete understanding of cyclical unemployment requires an explanation of countercyclical inflow rates as well as procyclical outflow rates.
\end{abstract}

Michael W. Elsby

University of Michigan

Department of Economics

238 Lorch Hall

611 Tappan Street

Ann Arbor, MI 48109-1220

and NBER

elsby@umich.edu

Ryan Michaels

Department of Economics

University of Michigan

Ann Arbor, MI 48109-1220

rmikes@umich.edu

\author{
Gary Solon \\ Department of Economics \\ University of Michigan \\ Ann Arbor, MI 48109 \\ and NBER \\ gsolon@umich.edu
}




\title{
The Ins and Outs of Cyclical Unemployment
}

\author{
1. Introduction
}

In principle, the increased unemployment during a recession could arise from an increase in the number of unemployment spells, an increase in the duration of unemployment spells, or both. Equivalently, one can decompose the cyclical variation in unemployment into changes in the rates of inflow to and outflow from unemployment. The title of a 1986 paper by Darby, Haltiwanger, and Plant dubbed this subject "The Ins and Outs of Unemployment.” Because Darby et al. claimed that cyclical unemployment variation in the United States stems almost entirely from cyclical variation in the inflow, their paper's subtitle was “The Ins Win.”

Contrary to that conclusion, one of the strongest trends in recent macroeconomic modeling of the labor market is to treat the inflow to unemployment as acyclical. In some instances, acyclicality of the inflow is assumed; in others, the model is designed to explain the supposed acyclicality of the inflow. Examples include Hall (2005a, 2005b), Gertler and Trigari (2006), Menzio and Moen (2006), Rotemberg (2006), and Blanchard and Gali (2006). Several of these authors motivate their treatment of the inflow as acyclical by referring to a pair of papers by Shimer (2005a, 2005b), which reach a conclusion diametrically opposite to that of Darby et al. For example, the introductory passage in the first of these, entitled "Reassessing the Ins and Outs of Unemployment," declares, "Using United States data from 1948 to 2004, I find that there are substantial fluctuations in unemployed workers' job finding probability at business cycle 
frequencies, while employed workers' separation probability is comparatively acyclic."1 Similar statements appear in Shimer (2005b and 2005c). ${ }^{2}$

Viewed in the context of a longer history of unemployment studies, the opposite conclusions of Darby et al. and Shimer both seem surprising. Darby et al.'s finding that "The Ins Win" and the outs lose appears to be contradicted by a large body of accumulated evidence suggesting that unemployment duration is substantially countercyclical:

- Regularly published statistics on the cross-sectional distribution of unemployment duration from the monthly Current Population Survey (CPS) show a pronounced shift towards longer unemployment spells during recessions. Similarly, sophisticated econometric analyses that have used repeated CPS cross-sectional data on unemployment duration to impute month-to-month hazard rates for exiting unemployment have found these outflow rates to be substantially procyclical (Sider, 1985; Baker, $1992^{3}$ ).

- Numerous studies have estimated inflow and outflow rates with the so-called gross flows data, which are based on the $2 / 3$ or so of the CPS sample that can be longitudinally matched from one month to the next. ${ }^{4}$ Without exception, these

\footnotetext{
${ }^{1}$ Shimer uses the term "separation probability" to mean the probability of entering unemployment. We do not use this terminology for two reasons. First, we wish to avoid confusion with the more commonly used meaning of "separation" as a quit or layoff from a particular employer, which often involves no unemployment at all (especially in the case of quits). Second, as we will emphasize in section 2.D of this paper, many spells of unemployment begin with entry into the labor force, not a separation from employment.

${ }^{2}$ Similarly, the abstract of Hall's Review of Economics and Statistics Lecture (2005b) says, "In the modern U.S. economy, recessions do not begin with a burst of layoffs. Unemployment rises because jobs are hard to find, not because an unusual number of people are thrown into unemployment."

${ }^{3}$ Baker's study, which disaggregated unemployment by reason for unemployment and demographic characteristics, directly refuted the conjecture by Darby et al. that the apparent cyclicality of unemployment duration could be explained mostly by cyclical changes in the composition of the unemployed.

${ }^{4}$ While the gross flows data are useful, they are not necessarily the data source of choice because they are plagued by numerous deficiencies, including the systematic exclusion of individuals who change residence
} 
studies have found that the monthly hazard rate for outflow from unemployment is procyclical (Perry, 1972; Marston, 1976; Blanchard and Diamond, 1990; Bleakley, Ferris, and Fuhrer, 1999; Fujita and Ramey, 2006; Yashiv, 2006).

- Regularly published statistics on unemployment insurance (UI) claims show that, during recessions, UI claims tend to be of considerably longer duration, and the fraction of claimants that exhaust their entitlement to benefits is considerably higher (Nicholson, 1981; Kennan, 2006). These facts, of course, are precisely why the federal government usually adopts extended-benefit programs during recessions.

Shimer's opposite conclusion that the outs win and the ins lose also appears to be contradicted by a great deal of evidence:

- The regularly published CPS statistics on unemployment duration show that the number unemployed less than five weeks (who therefore became unemployed since the previous month's CPS) tends to be substantially higher during recessions.

- The same studies of CPS gross flows data that have found procyclical flows out of unemployment also have found substantially countercyclical flows into unemployment. $^{5}$

\footnotetext{
and the many spurious transitions generated by misclassification in either of the months used in the longitudinal match. See National Commission on Employment and Unemployment Statistics (1979, pp. 214-17) and Barkume and Horvath (1995).

${ }^{5}$ The familiar finding of substantial cyclicality in both directions of gross flows between employment and unemployment is replicated in section 3 of Shimer (2005a). In our paper, instead of reanalyzing the gross flows data still again, we concentrate on replicating, extending, and interpreting the main analysis in Shimer's section 2, which his first page describes as the basis of his "preferred measures."
} 
- Regularly published statistics on initial UI claims show that dramatically more UI claims are initiated during recessions, especially early in recessions (Kennan, 2006). This, of course, is why the Conference Board uses initial UI claims as one of its "leading indicators."

- All these indications of countercyclical inflows into unemployment dovetail with well-established facts about labor turnover, including the recent employer-based evidence on countercyclical job destruction as well as a long history of evidence that layoffs are strongly countercyclical (Barth, 1971; Davis, Faberman, and Haltiwanger, 2006). ${ }^{6}$

Reacting to the apparent discrepancy between these patterns and Shimer's influential conclusion, in this paper we reassess Shimer's reassessment. Shimer's preferred analysis uses an ingenious methodology to infer the unemployment inflow and outflow rates from only three published monthly time series from the CPS: the number employed, the number unemployed, and the number unemployed less than five weeks. As Shimer rightly emphasizes, one of the virtues of his approach is "making it easy for others to verify my results, extend them as more data become available, and examine their consistency both within the United States and across countries." Thanks to the public availability of the data and the transparency of Shimer's method, we can indeed replicate and extend his analysis.

\footnotetext{
${ }^{6}$ As noted by Hall (2006), the countercyclicality of layoffs is no greater than the procyclicality of quits. This point was previously documented by Slichter (1919), Woytinsky (1942), Akerlof, Rose, and Yellen (1988), Anderson and Meyer (1994), and others. Davis (2006) clearly explains why distinguishing layoffs from quits is important for understanding cyclical fluctuations in the labor market.
} 
We confirm his finding that the majority of cyclical unemployment variation can be attributed to cyclicality in the outflow hazard, but we also find that, when viewed in an appropriate metric, Shimer's own results indicate that increased inflows also are important in most recessions, especially the most severe ones. We then propose and implement modifications of Shimer's methods for treating the 1994 CPS redesign, time aggregation bias, and heterogeneity in flow rates across job losers, job leavers, and labor force entrants. All our refinements of Shimer's analysis continue to find substantial cyclicality in both inflows and outflows.

In light of that finding, we caution against the recent tendency of macroeconomic theorists to overlook the cyclicality of unemployment inflows. A complete understanding of cyclical unemployment requires an explanation of countercyclical unemployment inflow rates as well as procyclical outflow rates. We also discuss more generally what can be learned about the business cycle from performing mechanical decompositions of cyclical unemployment variation into inflow and outflow components. We explain why some of the cyclical variation in the outflow hazard may be caused by cyclical changes in the size and composition of the inflow, and we suggest that cyclical changes in both inflows and outflows stem from the same source - whatever it is that shifts the derived demand for labor leftward during a recession.

\section{Replication, Reinterpretation, and Extension of Shimer's Main Analysis}

\section{A. Some Useful Identities}

Shimer starts with the following description of the evolution over time of the number unemployed: 


$$
\frac{d u}{d t}=s_{t}\left(l_{t}-u_{t}\right)-f_{t} u_{t}=-\left(s_{t}+f_{t}\right)\left(u_{t}-u_{t}^{*}\right)
$$

where $l_{t}$ and $u_{t}$ are the labor force and unemployment stocks respectively, $u_{t}{ }^{*}$ is steady state unemployment, and $s_{t}$ and $f_{t}$ are the unemployment inflow and outflow hazard rates. It should be mentioned at the outset that equation (1) accurately describes the evolution of unemployment only if all inflows into unemployment originate from employment. In fact, however, around $40 \%$ of the stock of unemployed workers report that their unemployment originated from non-participation in the labor force. We will address this issue in detail in section 2.D, but for now we maintain Shimer's simplifying assumption.

The focus of interest, then, is on the two flow rates $s_{t}$ and $f_{t}$. As many previous studies have shown, and as we will confirm, since $\left(s_{t}+f_{t}\right)$ is typically close to 0.5 on a monthly basis, the half life of a deviation from steady state unemployment is close to one month. In other words, the evolution of the actual unemployment rate, which we denote $\tilde{u}$, is closely approximated by the steady state unemployment rate:

$$
\tilde{u}_{t} \equiv \frac{u_{t}}{l_{t}} \approx \frac{u_{t}^{*}}{l_{t}}=\frac{s_{t}}{s_{t}+f_{t}}
$$

In what follows, a recurring theme will be the decomposition of changes in the observed unemployment rate into a contribution due to changes in the inflow rate and a contribution due to changes in the outflow rate. It turns out that equation (2) provides us with a remarkably simple decomposition. In particular, log differentiation of (2) yields

$$
d \log \tilde{u}_{t} \approx\left(1-\tilde{u}_{t}\right)\left[d \log s_{t}-d \log f_{t}\right]
$$

Equivalently, multiplying (3) through by $\tilde{u}_{t}$ yields

$$
d \tilde{u}_{t} \approx \tilde{u}_{t}\left(1-\tilde{u}_{t}\right)\left[d \log s_{t}-d \log f_{t}\right]
$$


Expressed in either way, the equation provides a decomposition in which the contributions of the inflow and outflow rates are separable and may be compared on an equal footing with respect to their impact on the unemployment rate. ${ }^{7}$ To obtain a transparent view of the relative contributions of the inflow and outflow rates, all one need do is compare the log variation in the two flows. In what follows, we will emphasize the formulation in (3) because, with $1-\tilde{u}_{t}$ close to 1 , the log changes in $s_{t}$ and $f_{t}$ translate almost one-to-one into proportional changes in the unemployment rate.

\section{B. Replication and Reinterpretation of Shimer's Original Analysis}

As noted by Shimer, a significant virtue of his methodology is the ease of its replication. In this spirit, we use the same, publicly available, seasonally adjusted CPS data on the number employed, the number unemployed, and the number unemployed less than five weeks (henceforth "short-term unemployment") for each month from 1948 through $2004 .^{8}$

Shimer's analysis involves two corrections to these time series. First, as discussed by Polivka and Miller (1998) and Abraham and Shimer (2001), the 1994 redesign of the CPS changed the way the survey measures unemployment duration for all of the survey's eight "rotation groups" except the first and fifth. ${ }^{9}$ The resulting reduction

\footnotetext{
${ }^{7}$ In contrast, it is more difficult to interpret the "counterfactual" analysis performed in Shimer's paper. In particular, to assess the importance of the outflow rate in explaining changes in unemployment, he calculates the unemployment rate that would have prevailed if the inflow rate were always at its temporal mean, $\bar{s} /\left(\bar{s}+f_{t}\right)$. Clearly, however, a different answer would obtain if the inflow rate were held constant at a different value.

${ }^{8}$ These data are readily obtained from the Bureau of Labor Statistics website, www.bls.gov.

${ }^{9}$ In the CPS sample design, an address selected into the sample remains in the sample for four consecutive months, is temporarily rotated out of the sample for eight months, and then is rotated back in for four more months before being permanently retired from the sample. The first and fifth rotation groups are respectively the addresses in the survey for the first time and those reentering after the eight-month hiatus.
} 
in the number counted as short-term unemployed induced a discontinuity in the series.

Shimer's main method of correcting for the discontinuity is, in each month from 1994 on, to inflate the official count of short-term unemployment by that month's ratio of the short-term share of unemployment in the first and fifth rotation groups (obtained from the CPS microdata) to the short-term share for the full sample. Equivalently, he multiplies the official count of all unemployment by the short-term share in only the first and fifth rotation groups. This treats the discontinuity because, even since 1994, the first and fifth rotation groups' unemployment duration has been measured in the same way as the full sample's was before 1994. In this section's replication, we use Shimer's correction method, but in section 2.C we will implement a variation of the method that we believe is even better.

Second, instead of just using the monthly time series to calculate monthly transition rates, Shimer devises an ingenious way of inferring continuous-time inflow and outflow hazard rates, $s_{t}$ and $f_{t}$. Inferring the outflow hazard rate is relatively straightforward. First calculate the probability that a typical unemployed worker leaves unemployment in the month between consecutive CPS surveys, $F_{t}$, using the identity

$$
\Delta u_{t+1}=u_{t+1}^{s}-F_{t} u_{t}
$$

where $\Delta u_{t+1}$ is the monthly change in the number unemployed between month $t$ and month $t+1$, and $u_{t+1}{ }^{s}$ is the number unemployed less than five weeks in month $t+1$.

The crucial change in the 1994 redesign was that, in all rotation groups except the first and fifth, unemployed individuals who also were unemployed as of the previous month's interview were no longer asked about their unemployment duration. Instead, their unemployment duration was measured as the previous month's value incremented by the number of weeks between the two monthly interviews. 
Thus, the monthly outflow probability is given by $F_{t}=1-\frac{u_{t+1}-u_{t+1}^{s}}{u_{t}}$. This can then be mapped into the outflow hazard, $f_{t}=-\log \left(1-F_{t}\right)$.

Inferring the inflow hazard is more difficult. The reason is that some workers who flow into the unemployment pool after one month's CPS also exit unemployment before the next month's survey. As a result, the measured stock of short-term unemployed workers in any CPS is in fact an underestimate of the number of workers who flowed into the unemployment pool over the course of the preceding month. The latter is what Shimer refers to as time aggregation bias. ${ }^{10}$

To correct for time aggregation bias, Shimer solves (1), the differential equation for the evolution of the unemployment rate, forward one month under the assumptions that the flows, $s_{t}$ and $f_{t}$, and the labor force, $l_{t}$, are constant between surveys:

$$
u_{t+1}=u_{t}^{*}+\left(u_{t}-u_{t}^{*}\right) \exp \left[-\left(s_{t}+f_{t}\right)\right]
$$

Since we obtain a measure of the outflow rate $f_{t}$ from the method above, and since we observe $u_{t}$ and $u_{t+1}$, the unemployment rates at the beginning and end of the month, we can solve (6) for the inflow hazard $s_{t}$.

Following Shimer's method provides us with measures of the inflow and outflow rates for each month from 1948 through 2004. As a final step, to obtain what Shimer refers to as his preferred measures of unemployment inflow and outflow rates, we take quarterly averages of these monthly series to obtain smoother series.

\footnotetext{
${ }^{10}$ Note that there is no analogous time aggregation problem in the measurement of unemployment outflows due to unemployed workers leaving unemployment and re-entering between CPS surveys. The reason is that the CPS in theory picks up all such workers, as they will be measured as unemployed less than five weeks.
} 
In our figure 1 we replicate Shimer's figure 1 and display the quarterly time series of the probabilities of flowing in or out of unemployment over the course of a month based on Shimer's methodology. To the untrained eye, figure 1 might give the impression that the cyclical variation in the inflow to unemployment is dwarfed by the variation in the outflow from unemployment. However, a key lesson from equation (3) in our section 2.A is that a more apt comparison is between the variation in the logarithms of the inflow and outflow hazard rates. Figure 2 displays these log flows. Note that, since the range of the vertical axes measuring these two log flows is the same, equalsized variation in either plot will have an equal-sized impact on the log unemployment rate.

Inspection of figure 2 reveals substantial variation in log inflow rates in all recessions except the two most recent (the relatively mild 1990 and 2001 recessions). Thus it is by no means clear that the inflow rate into unemployment is, in Shimer's words, "comparatively acyclic" relative to the outflow rate, except in these recent recessions.

A natural question at this point is what fraction of the increase in unemployment during a recession is due to increases in the inflow rate into unemployment, and what fraction is due to declines in the outflow rate? Thanks to the decomposition presented in section 2.A, such a question is straightforward to answer. We first identified start and end dates for the unemployment ramp-up in each recession from 1948 on. ${ }^{11}$ We then

\footnotetext{
${ }^{11}$ In practice, the start dates were determined by the most recent minimum quarterly unemployment rate preceding each NBER recession start date, and the end dates by the highest quarterly unemployment rate following each NBER recession end date. The NBER recession dates were not used as their focus is not on recessionary unemployment, but rather principally on GDP growth, and they thereby miss a large portion of the cyclical ramp-up in unemployment. Figure 0 displays these dates along with the time series for the unemployment rate.
} 
calculated the difference in the log inflow rate and $\log$ outflow rate relative to their startof-recession values for each recession in turn. Figure 3 plots the change in the log inflow rate and the negative of the change in the log outflow rate (in accordance with equation (3)) for each quarter of each recession since 1948 using our replication of Shimer's preferred data.

Figure 3 reveals a number of insights. First, consistent with Shimer's results, we observe that the outflow rate from unemployment fell in most recessions by about 30 to $50 \log$ points. Thus, variation in the outflow rate from unemployment is a crucial aspect of cyclical unemployment. And it is true that the outflow rate explains the majority of the cumulative peak-to-trough rise in unemployment over the cycle, with a greater relative impact later on in a recession.

However, figure 3 confirms that inflow rates also have played a substantial role in generating cyclical unemployment historically. In particular, we observe that the inflow into unemployment typically rose by around 20 to $40 \log$ points from peak to trough, except in the last two recessions. ${ }^{12}$ We also observe that the effects of inflows tend to be strongest at the start of recessions, in contrast to the effects of the outflow rate. Thus, graphed in an appropriate metric, Shimer's own data show that, until the two recent recessions, there was something like a 35:65 inflow/outflow split of the overall increase in unemployment, with relatively more weight on inflows earlier on and outflows later on in a recession. Thus, Shimer's claim that the inflow rate is "nearly acyclical" is an overstatement at best.

\footnotetext{
${ }^{12}$ For both outflows and inflows, the changes in log points appear small in the major recession period of the early 1980s because we break the period into two separate recessions.
} 
Figure 3 also highlights the difference in unemployment patterns between the last two recessions and the many prior recessions. In the last two recessions, especially the one of the early 1990s, aggregate inflows into unemployment moved comparatively little. Thus, weak aggregate inflow effects, as measured in Shimer's preferred analysis, appear to be a feature of these last two recessions rather than a stylized fact of recessionary unemployment as a whole. In any case, in the next two sections, we shall see reasons to question figure 3's depiction of the most recent recessions. In section 2.C, we shall see that the apparent weakness of inflow effects in the 2000/01 recession varies with the method of correcting for the CPS redesign. And our disaggregate analysis in section 2.D will reveal that the aggregate picture presented in figure 3 masks some important heterogeneity in the effects of different inflow rates for different sub-groups of the unemployed. In the end, the inflow effects in the last recession will not look so different from those in prior recessions.

\section{Modifications of Shimer's Correction Methods}

Shimer's analysis is based on publicly available data from the CPS, but it also depends on the particular corrections he makes for the CPS redesign and time aggregation bias. We agree that corrections are called for and that Shimer's correction methods are reasonable first steps, but we also think the methods can be improved on. In this section, we propose refinements of the correction methods and present the results from applying them.

As mentioned above, to treat the discontinuity in the short-term unemployment series induced by the 1994 CPS redesign, Shimer multiplies the official unemployment 
count in each month from 1994 on by the month's short-term share of unemployment for only the first and fifth rotation groups, whose unemployment duration measurement was unaffected by the redesign. As Shimer acknowledges in his appendix, a drawback of this approach is that it bases each month's estimated short-term share on only about onequarter of the unemployed in the CPS sample and therefore multiplies the sampling variance of the estimate by about four. The resulting noise in the corrected series can make it more difficult to discern the true cyclical variation in unemployment flows since 1994. This noise from sampling error would get worse still in our section 2.D, when we disaggregate the unemployed into job losers, job leavers, and labor force entrants.

An alternative approach that can yield a more stable corrected series for shortterm unemployment over the post-redesign era is to multiply the official short-term unemployment series by the era's average of the ratio of the short-term share for the first and fifth rotation groups to the full sample's short-term share. Indeed, in footnote 27 of his appendix, Shimer's mentions an alternative analysis in which he multiplied the postredesign short-term unemployment by a constant correction factor of 1.10 , but he does not explain his choice of 1.10 . Statistics he reports in his appendix seem to indicate that $44.2 / 37.9=1.166$ would be a more appropriate choice. Our own analysis of CPS microdata from February 1994 (the first month that unemployment duration was measured in the new way for all rotation groups except the first and fifth) through January 2005 finds an average ratio of $1.1549 .{ }^{13}$ We therefore produce a less noisy postredesign series by simply multiplying the official short-term unemployment by 1.1549 in each month from February 1994 on.

\footnotetext{
${ }^{13}$ Based on different information from the CPS "parallel survey," Polivka and Miller (1998) suggest an even higher correction factor of $1 / .830=1.205$.
} 
To get a sense of the practical difference between Shimer's and our methods of correcting for the CPS redesign, Figure 4 plots the month-by-month scaling factor used by Shimer, together with our scaling factor. It can be seen that the month-by-month correction factor displays considerable volatility and little obvious systematic trend around our correction factor of 1.1549 .

Figure 5 displays the effects of our alternative redesign correction on the decomposition of cyclical unemployment in the last recession, along with the previous five recessions by way of comparison. It can be seen that our less noisy correction for the 1994 redesign reveals a substantially more pronounced effect of the inflow rate in the 2001 recession. In particular, the inflow contribution in the last recession no longer looks so different from the inflow contributions in some of the earlier recessions.

Shimer's other correction seeks to avoid the time aggregation bias that would result from missing unemployment spells that begin after one month's CPS and end before the next month's survey. As explained in our section 2.B, Shimer's approach is to impute continuous-time hazard rates for the unemployment inflow. The trouble with this approach is that it is at odds with the discrete weekly nature of the CPS labor force definitions. Each month's CPS interviews take place during the week containing the $19^{\text {th }}$ of the month, and the labor force questions pertain to the "reference week" containing the $12^{\text {th }}$. Someone who works at any time during the reference week is counted as employed. In contrast, a continuous-time perspective views someone who quits one job effective 5:00 pm. on Friday and starts a new job at 9:00 a.m. the following Monday as unemployed every instant between those two times. That definition of an unemployment 
spell is debatable and, in any case, is inconsistent with the official labor force definitions underlying the employment and unemployment series that we and Shimer are analyzing.

We therefore propose a discrete weekly analog to Shimer's correction method, which deals with time aggregation bias in a way that coheres with the official labor force definitions. The details are in our appendix. Similarly to Shimer's correction, ours boils down to the solution to a non-linear equation in the weekly inflow probability $s_{t}{ }^{w}$, and the weekly outflow probability, $f_{t}^{w}$ :

$$
u_{t+1}=u_{t}^{w^{*}}+\left(u_{t}-u_{t}^{w^{*}}\right)\left(1-s_{t}^{w}-f_{t}^{w}\right)^{4}
$$

where $u_{t}^{w^{*}}$ is the steady-state weekly unemployment stock.

Figure 6 illustrates both the discrete-time and continuous-time (Shimer) corrected $\log$ inflow hazard rates, along with the uncorrected inflow rate for comparison. ${ }^{14}$ As expected, both aggregation bias corrections raise the level of estimated inflow rates, since they seek to add back on inflows that subsequently exited unemployment between survey dates. In particular, the continuous-time correction increases the level of the measured inflow rate by about $30 \log$ points, while the discrete-time correction does so by around $23 \log$ points. Thus, Shimer's continuous-time correction arguably over-corrects for time aggregation bias in the sense that it imputes short unemployment spells that the official statistics would not recognize as unemployment spells even if the CPS took place every single week.

In addition, figure 6 reveals that, since the aggregation bias corrections raise the level of estimated inflow rates, they reduce the log change in the inflow rate over the

\footnotetext{
${ }^{14}$ To isolate the effects of the alternative corrections for time aggregation bias, all the series plotted in figure 6 use our correction for the 1994 redesign.
} 
cycle. ${ }^{15}$ Simple least squares regressions of corrected log inflow rates on the uncorrected $\log$ inflow rate reveal coefficients of 0.78 for Shimer's continuous-time correction and 0.85 for the discrete-time correction, consistent with the notion that correcting for aggregation bias limits the capacity for inflows to explain cyclical unemployment. The latter also reveals that, because the weekly correction affects the inflow level to a lesser extent than the continuous-time correction, it also preserves more of the log variation in inflow rates over time, and thereby in theory affords greater potential for inflows to explain cyclical unemployment.

Figure 7 compares the inflow contributions implied by the two alternative corrections for aggregation bias, as well as the contributions based on no correction at all. ${ }^{16}$ The starkest finding is that failing to correct for time aggregation bias does indeed apportion a greater role to the inflow rate, and therefore correcting for that bias is important. It is also true that the weekly correction places marginally greater emphasis on inflows than the continuous-time correction, but quantitatively the effects are small. Thus, the results based on the refined aggregation correction methods are broadly similar to those obtained in the aggregate analysis of section 2.B.

\footnotetext{
${ }^{15}$ Strictly speaking, this occurs for a slightly different reason from that highlighted by Shimer, who argues that "ignoring time aggregation will bias a researcher towards finding a countercyclical separation probability, because when the job finding probability falls, a worker who loses her job is more likely to experience a measured spell of unemployment." In fact, we find that the aggregation bias corrections have little effect on the countercyclicality of the level of the inflow rate. But, by raising the overall level of the inflow rate, they reduce the countercyclicality of the log inflow rate, which is what matters for the statistical decomposition of cyclical variation in unemployment.

${ }^{16}$ For all three of these approaches to time aggregation bias, this figure's contributions for the most recent recession are based on our correction for the 1994 CPS redesign.
} 


\section{Disaggregation by Reason for Unemployment}

Until now, we have been concentrating on aggregate unemployment flows based on Shimer's preferred analysis. As noted at the beginning of section 2.A, however, Shimer's analysis ignores that almost half of unemployment comes from nonparticipation in the labor force, not employment. In this section, we extend the analysis to incorporate flows from non-participation. At the same time, we also distinguish employment-to-unemployment flows stemming from job loss and from job leaving, as these two flows have very different cyclical properties.

The disaggregated analysis in this section uses data on the number unemployed by reason, the number unemployed for less than five weeks by reason, and aggregate series for employment and non-participation. Our disaggregation of unemployment by reason uses three categories: job losers, job leavers, and labor force entrants. ${ }^{17}$ The complete requisite series for short-term unemployment by reason are not available on the BLS website, so we have based this section's analysis on data from the monthly BLS Employment and Earnings publications. Even those data for short-term unemployment by reason extend back only to May 1968 and are not seasonally adjusted. For internal consistency, we start with the seasonally unadjusted Employment and Earnings data for all the series used in this section. As in section 2.C, we treat the 1994 discontinuity in the short-term unemployment series by multiplying each published short-term unemployment number from February 1994 on by an average ratio of the short-term share of

\footnotetext{
${ }^{17}$ We do not further disaggregate job losers into temporary layoffs and permanent job losers for two reasons. First, the temporary layoff information is available only back to 1976. Second, as explained in Polivka and Miller (1998), the 1994 CPS redesign caused a discontinuity in the way the two types of job losers are distinguished. Similarly, we do not disaggregate labor force entrants into new entrants and reentrants because the 1994 redesign instituted a major change in the way the two types of entrants are distinguished.
} 
unemployment in the first and fifth rotation groups to the corresponding short-term share for the full sample. In particular, based on the CPS microdata from February 1994 through January 2005, we calculate correction factors of 1.0958 for job losers, 1.1644 for job leavers, and 1.2272 for labor force entrants. Finally, we seasonally adjust all the series with Eviews' implementation of the Census Bureau's X-12 procedure.

Given the resulting data, it is again straightforward to calculate monthly outflow probabilities for each reason for unemployment. Specifically, for each reason we can calculate $F_{r t}=1-\frac{u_{r, t+1}-u_{r, t+1}^{s}}{u_{r t}}$, where a subscript $r$ denotes reason. And, as in the aggregate case, we can calculate the associated outflow hazards by reason, $f_{r t}=-\log \left(1-F_{r t}\right)$. As detailed in our appendix, we treat time aggregation bias with an extension of our discrete-time correction, which produces a corrected inflow hazard $s_{r t}$ for each type of unemployment.

Figure 8 displays the time series for each of these inflow rates. It reveals stark heterogeneity in the cyclical properties of the three inflow hazards. The job loser inflow is clearly countercyclical, displaying prominent upward spikes in all recessions. By contrast, the job leaver inflow rate is prominently procyclical (which is not so surprising given the procyclicality of quit rates noted above in footnote 6). Finally, the inflow from non-participation is comparatively acyclical.

The latter three observations might come as no surprise to a reader of the past literature on labor flows, or indeed to any non-economist for that matter. However, it has an important implication with respect to Shimer's analysis. Concentrating on the aggregate inflow rate conflates loser and leaver inflows that move in opposite directions 
over the cycle, and in addition it averages them with a broadly acyclical inflow of entrants. Looking only at an aggregate inflow has the effect of masking the individual contributions of each of these inflow rates that move in different cyclical directions.

Figure 9 displays the analogous results for outflow rates by type. This figure exhibits two types of heterogeneity. First, job losers show considerably lower outflow rates (and hence longer unemployment spells) than do leavers and entrants. This fact combined with the countercyclicality of losers' share of the inflow constitutes the kernel of truth in the argument by Darby, Haltiwanger, and Plant (1986): One reason the aggregate outflow rate declines in a recession is the increased inflow share of job losers, whose outflow rates are relatively low. As shown by Baker (1992) (and reaffirmed in Shimer's section 4), however, this composition effect is not nearly strong enough to justify Darby, Haltiwanger, and Plant's conclusion that "The Ins Win." Interpreted in the framework of our equation (3), the estimates in Baker's tables 1 and 3 indicate that adjusting for this composition effect decreases the share of cyclical unemployment due to cyclicality in outflow rates from 57 percent to 49 percent. Thus, Baker's results are altogether consistent with our conclusion that both the ins and outs of unemployment are empirically important.

Second, figure 9 shows that the outflow rate is especially procyclical for job losers. Because the outflow rate also is quite procyclical for the other two types of unemployed, though, aggregating the various outflow rates is much less problematic than aggregation of the inflows.

To get a sense of the individual contributions of each of the inflow and outflow rates by reason, we again seek to decompose the change in the log unemployment rate 
into components due to each of the flows. To this end, note first that we can split the aggregate unemployment rate into the sum of the unemployment rates for each reason, $\tilde{u}=\tilde{u}_{\lambda}+\tilde{u}_{q}+\tilde{u}_{e}$, where subscripts $\lambda, q$, and $e$ refer to job losers, job leavers (quits), and labor force entrants respectively. Log differentiation of the latter reveals that the change in the log unemployment rate is equal to the share-weighted sum of the log changes in the constituent sub unemployment rates:

$$
d \log \tilde{u}=\omega_{\lambda} d \log \tilde{u}_{\lambda}+\omega_{q} d \log \tilde{u}_{q}+\omega_{e} d \log \tilde{u}_{e}
$$

where $\omega_{r}$ is the unemployment share of reason $r$. In steady state, the three sub unemployment rates are given by

$$
\begin{aligned}
& \tilde{u}_{\lambda}=s_{\lambda} e / f_{\lambda} \Rightarrow d \log \tilde{u}_{\lambda}=d \log s_{\lambda}-d \log f_{\lambda}+d \log e \\
& \tilde{u}_{q}=s_{q} e / f_{q} \Rightarrow d \log \tilde{u}_{q}=d \log s_{q}-d \log f_{q}+d \log e \\
& \tilde{u}_{e}=s_{e} i / f_{e} \Rightarrow d \log \tilde{u}_{e}=d \log s_{e}-d \log f_{e}+d \log i
\end{aligned}
$$

where $e$ and $i$ denote employment and non-participation as a fraction of the labor force. It turns out that the log variation in both $e$ and $i$ over time is minuscule relative to the cyclical variation in log unemployment (see figure 10). Thus, a very good approximation over the few quarters represented by a recessionary ramp-up in unemployment is that $d \log e \approx 0 \approx d \log i$. This yields the following very simple approximate decomposition:

$$
d \log \tilde{u} \approx \omega_{\lambda}\left[d \log s_{\lambda}-d \log f_{\lambda}\right]+\omega_{q}\left[d \log s_{q}-d \log f_{q}\right]+\omega_{e}\left[d \log s_{e}-d \log f_{e}\right]
$$

Figure 11 displays the results of this decomposition. Specifically, it plots the contribution of each unemployment flow, for each reason, for each recession since 1969. The contribution of each flow is measured, in accordance with equation (10), by multiplying the difference in the log flow relative to its start of recession value by the initial share in unemployment of that flow at the start of the recession. 
The results of this exercise reveal that there is a great deal of richer detail underlying the aggregate analyses performed by Shimer and ourselves. First and foremost, the decomposition indicates that the most important flow in all but the last two recessions was the job loser inflow rate. In addition, the job loser inflow contributed to a non-trivial degree in the 1990 recession, and was very prominent in the first five quarters of the 2001 unemployment ramp-up. ${ }^{18}$ Thus, recent claims such as "In the modern U.S. economy, recessions do not begin with a burst of layoffs" (Hall, 2005b) are not supported by the CPS data. ${ }^{19}$

Moreover, figure 11 confirms that the aggregate picture presented in figure 3 masks important heterogeneity in the cyclical effects of each individual inflow rate. Specifically, it can be seen that the contribution to recession unemployment due to job leavers is systematically negative because the leaver inflow rate is procyclical. This serves to offset part of the increase in unemployment due to increased job loss.

Figure 11 also provides some insight into why the aggregate inflow rate performs relatively poorly in explaining the increase in unemployment in recent recessions. The contribution of the inflow rate from non-participation declined from a positive effect in the 1969,1973 , and 1979 recessions, to mildly positive in the 1981 and 1990 recessions, to negative in the 2001 recession. This is important to emphasize as, from a theoretical perspective, macroeconomists are typically most interested in unemployment inflows that

\footnotetext{
${ }^{18}$ Note that our choice to weight by pre-recession unemployment shares errs on the side of understating the importance of the job loser inflow.

${ }^{19}$ Hall's conclusion is based partly on the Job Openings and Labor Turnover Survey (JOLTS). Because JOLTS began in December 2000, it missed part of the ramp-up to the most recent recession. Furthermore, the JOLTS data for that recession seem to be at odds with information from other surveys, including our evidence from the CPS. A careful comparison of what multiple sources of labor market data have to say about the last recession would be a very worthwhile research project.
} 
originate from employment rather than non-participation. Indeed, Shimer's practice of referring to the unemployment inflow rate as the "separation rate" reflects this focus.

Turning to outflows, we can see from figure 11 that the reason aggregate outflows explain so much of the variation in unemployment is because all of the constituent outflows by reason cause unemployment to move in the same direction - that is, up in a recession. In addition, we see that the most important outflow is the outflow rate for job losers. This is to be expected, as job losers represent a substantial fraction of the unemployment pool. That aside, however, the losers outflow rate is conspicuously dominant in the 1990 recession, again suggesting that this recession was especially different from the others in the sample period.

A question that arises at this point is the extent to which the disaggregated analysis is important. Surely, one might argue, it nevertheless aggregates to the same story mentioned in section 2.B? Our view, however, is that the disaggregated analysis culminating in figure 11 affords a more nuanced and illuminating view of unemployment flows, especially with regard to the inflows. It is not clear what economic hypothesis is being assessed when one observes the cyclicality of the aggregate inflow rate, which is a weighted average of a number of sub-inflow rates. However, the economics becomes clearer, and very intuitive, when one looks at inflows by reason. The job leaver inflow into unemployment falls in all recessions for the same reason that the quit rate does presumably because workers find it harder then to find attractive new jobs. The job loser inflow rate rises in all recessions for the same reason that the layoff rate does - because firms want to employ fewer workers in a recession; they are unable (especially in the more severe recessions) to achieve the intended employment reductions merely by 
allowing workers to quit; and they therefore lay off more workers, many of whom then experience unemployment.

\section{Summary and Discussion}

Our effort to replicate and extend Shimer's "Reassessing the Ins and Outs of Unemployment" has confirmed that procyclicality of the hazard rate for exiting unemployment plays an important role in cyclical unemployment. Contrary to Shimer's conclusions, however, we have shown that even his own methods and data also indicate an important role for countercyclical inflows into unemployment. This finding is further strengthened by our refinements of Shimer's methods of correcting the official Current Population Survey labor force series for the 1994 redesign of the CPS and for time aggregation bias. In addition, we have conducted a disaggregated analysis that recognizes the large unemployment inflows from non-participation in the labor force and also distinguishes employment-to-unemployment inflows stemming from job losing and job leaving. The disaggregated results highlight the particularly important role of job loss inflows to unemployment in accounting for increased unemployment in most recessions. Thus, in contrast to both Darby et al.'s (1986) pronouncement that “The Ins Win" and Shimer's opposite conclusion that the outs win, we find that everyone's a winner.

At a basic level, then, our paper suggests that a complete understanding of cyclical unemployment requires an explanation of countercyclical unemployment inflow rates as well as procyclical outflow rates. Accordingly, the many recent analyses cited in our second paragraph that overlook cyclical inflows may be ill-advised. By the same 
token, earlier efforts to explain why unemployment inflows rise in a recession (e.g., Mortensen and Pissarides, 1994; Cole and Rogerson, 1999) remain potentially relevant.

In the remainder of this section, however, we want to emphasize that the precise economic interpretation of statistical decompositions such as equation (3) is not as clear as it might seem. Up until now, we have followed the literature in interpreting the decompositions as answering the question "how much of the increase in unemployment in a recession is due to changes in inflows and outflows." In what follows, we show that such an interpretation is not the only possible reading of decompositions based on (3), and that different models of the labor market imply different interpretations.

We motivate this point with the following metaphor. Imagine a traffic intersection at which a queue of automobiles awaits a green light. The light stays green long enough in each cycle to allow an outflow of five cars to leave the queue before the light turns red again. Ordinarily, only a moderate number of cars is backed up at the light. But suppose some event - say, construction on an alternate route - ramps up the inflow of cars to this intersection. If nothing happens to keep the green light on longer, then the queue gets longer, and each car's wait to get through the intersection becomes longer.

Now just for the moment, think of the queue of backed-up cars as unemployment, and think of the five cars going through each green light as the outflow from unemployment. When the inflow increased, the stock of unemployment increased, and so did the average duration of unemployment. If an analysis such as ours or Shimer's were applied here, it would attribute much of the increased unemployment to a decreased exit rate even though nothing actually changed in the outflow process. The proximate 
cause of both the increased unemployment level and the increased duration was the increased inflow. ${ }^{20}$

Thus, the traffic metaphor illustrates a possibility worth considering when reacting to statistical decompositions of the ins and outs of unemployment. Although analyses like ours and Shimer's attempt to separate the contributions of inflows and outflows, the inflows and outflows may be inherently inseparable. It could be, for example, that congestion from increased inflows causes outflow hazard rates to become lower. $^{21}$

This latter possibility has received little attention in the previous literature on unemployment flows, perhaps because of the literature's focus on search and matching models of the aggregate labor market (Pissarides, 1985; Mortensen and Pissarides, 1994). In these models, the number flowing out of unemployment is increasing in the number of unemployed workers, as well as in the number of job vacancies. The matching function that describes this relationship is meant to capture frictions that prevent firms and workers from quickly finding (suitable) partners for an employment relationship. Under the typical specification of this matching function, a greater number of unemployed workers (the denominator of the outflow hazard) will raise the number flowing out of unemployment (the numerator of the outflow hazard) so that the outflow rate will not itself depend on the number unemployed. Put in the language of the traffic metaphor, the green light stays on longer when more cars are waiting at the intersection. According to

\footnotetext{
${ }^{20}$ Note also that, just as the wait until going through the green light would increase for all cars regardless of whether they had arrived from the usual route or from the obstructed alternate route, unemployment duration would increase for all the unemployed - job losers, job leavers, and labor force entrants - just as found in the analyses by Baker (1992), Shimer, and ourselves.

${ }^{21}$ Another example of interaction between inflows and outflows, discussed above in section 2.D, is that cyclical changes in the composition of the inflow to unemployment (especially the increased share of permanent job losers) cause a modest reduction in the outflow rate.
} 
these models, then, changes in the outflow hazard will be driven only by exogenous variables, notably labor productivity. ${ }^{22}$ In this theoretical framework, the mechanism encapsulated in the traffic metaphor does not arise.

That particular theoretical perspective, however, is not the only conceivable economic interpretation of cyclical flows in the labor market. Consider, for example, an alternative model in which firms face no friction in hiring unemployed workers; that is, firms may hire as many unemployed workers as they wish without incurring important search costs. ${ }^{23}$ Then, given labor productivity, firms will choose directly the number of workers to hire out of the unemployment pool. In the language of the traffic metaphor, how long the green light stays on is not determined by the number of cars waiting at the intersection. Then, as in the traffic metaphor, increased unemployment due to increased inflows can mechanically reduce outflow hazard rates during recessions.

Viewed through this lens, a more appropriate decomposition of unemployment flows might focus on changes in the level of the outflow, since these are independent of the number unemployed in the latter model. It turns out that simple algebraic manipulation of equation (3), our framework for decomposing cyclical unemployment variation into inflows and outflows, provides such a decomposition:

$$
d \log \tilde{u}_{t} \approx \frac{1-\tilde{u}_{t}}{\tilde{u}_{t}}\left[d \log s_{t}-d \log \left(f_{t} \tilde{u}_{t}\right)\right]
$$

This re-expression of equation (3) decomposes cyclical variation in log unemployment into an inflow component plus an outflow component involving the log change in the

\footnotetext{
${ }^{22}$ Indeed, Shimer (2005a, p. 23) makes this point to justify his emphasis on flow hazard rates, rather than the levels of the unemployment flows.

${ }^{23}$ Such an assumption may not be an entirely ludicrous approximation, as the average duration of a vacancy is consistently less than one month in the Bureau of Labor Statistics' JOLTS dataset.
} 
number flowing out of unemployment, $f_{t} \tilde{u}_{t}$ (instead of the hazard rate for the outflow, $f_{t}$ ). The monthly version of the latter is plotted in figure 12 , which illustrates a fact that may surprise some readers who have not encountered it before: Even though the hazard rate for exiting unemployment goes down in recessions, the number exiting unemployment goes up. This fact, acknowledged by Shimer (2005a, p. 22), was previously documented in the gross flows data analysis by Blanchard and Diamond (1990, p. 118): "While the flow from unemployment to employment increases in a recession, the hazard rate decreases as the pool of unemployed increases proportionately more than the flow."

Given the countercyclicality of the number exiting unemployment, if one viewed unemployment flows solely in terms of the model motivating equation (10), one would conclude that more than the entirety of the cyclical variation in unemployment is accounted for by countercyclical inflows. That is, one would declare that "The Ins Win" after all. Our point, however, is not to deny the importance of reduced outflow hazard rates in recessions. Our point is that, in order to assess the roles of inflows and outflows in cyclical unemployment, one must understand the economic determinants of both the ins and the outs.

We believe the challenge to future theoretical work is to develop coherent and plausible models that can account for the full range of relevant empirical evidence. In terms of the particular facts we hope to have clarified in this paper, theoretical analyses should explain why job-loss-induced inflows to unemployment increase at the beginning of a recession and why outflows do not increase enough to keep unemployment duration 
from rising. ${ }^{24}$ Our hunch is that cyclical movements in both the number of unemployment spells and their duration stem largely from shared causes. Like Hall (1988), we think of the relatively low employment (and real wages) during a recession as reflecting a leftward shift in the derived demand for labor along a positively sloped effective labor supply curve. Whatever it is that induces the leftward shift in labor demand motivates some firms to effect employment reductions through layoffs (many of which lead to unemployment) and also deters other firms from hiring enough to prevent a rise in the stock and duration of unemployment. If the effective short-run labor supply curve were perfectly inelastic, then wages would drop enough either to prevent the burst of layoffs or to induce some firms quickly to hire up the laid-off workers. Recognizing that real wage variation is not procyclical enough to prevent cyclical variation in employment and unemployment is another way of saying that the effective short-run labor supply curve is positively sloped rather than inelastic.

The key questions then become: (1) What causes labor demand to shift leftward during a recession, and (2) why is the effective short-run labor supply curve positively sloped? We suspect that the answers to these questions also will deliver straightforward answers to why cyclical unemployment variation divvies up as it does between changes in inflow and outflow rates.

\footnotetext{
${ }^{24}$ Of course, theoretical work also should endeavor to explain the cyclical features of other salient variables such as employment, hours of work, wage rates, vacancies, productivity, capital utilization, etc.
} 


\section{$\underline{\text { Appendix }}$}

Discrete-Time Correction for Time Aggregation Bias in Aggregate Inflows

We use an analogous method to Shimer's in discrete time. That is, we essentially use one difference equation, that for the total stock of unemployment:

$$
u_{t+\tau+1 / 4}=u_{t+\tau}+s_{t}^{w} e_{t+\tau}-f_{t}^{w} u_{t+\tau}
$$

where $s_{t}{ }^{w}$ and $f_{t}^{w}$ are the weekly inflow and outflow probabilities and are assumed

constant between interview dates, and where $\tau \in\left\{0, \frac{1}{4}, \frac{1}{2}, \frac{3}{4}\right\}$ indexes the intervening weeks. Like Shimer, we then make the further assumption that the labor force, $l_{t} \equiv e_{t}+u_{t}$, is also constant within the interval. This implies that we can rewrite (A.1) as:

$$
u_{t+\tau+1 / 4}=s_{t}^{w} l_{t}+\left(1-s_{t}^{w}-f_{t}^{w}\right) u_{t+\tau}
$$

Solving this equation forward four weeks yields the following non-linear equation:

$$
u_{t+1}=s_{t}{ }_{t} l_{n=0}^{3}\left(1-s_{t}^{w}-f_{t}^{w}\right)^{n}+\left(1-s_{t}^{w}-f_{t}^{w}\right)^{4} u_{t}
$$

Noting that the steady-state weekly unemployment stock in this model is given by $u_{t}^{w^{*}}=\frac{s_{t}^{w}}{s_{t}^{w}+f_{t}^{w}}$ yields equation (7) in the main text.

\section{Discrete-Time Correction for Time Aggregation Bias in Inflows by Reason}

The correction for inflows by reason is a simple extension to the above. Now there are three difference equations to solve out - one for unemployment by each reason:

$$
\begin{aligned}
& u_{\lambda, t+\tau+1 / 4}=u_{\lambda, t+\tau}+s_{\lambda, t}^{w} e_{t+\tau}-f_{\lambda, t}^{w} u_{\lambda, t+\tau} \\
& u_{q, t+\tau+1 / 4}=u_{q, t+\tau}+s_{q, t}^{w} e_{t+\tau}-f_{q, t}^{w} u_{q, t+\tau} \\
& u_{e, t+\tau+1 / 4}=u_{e, t+\tau}+s_{e, t}^{w} i_{t+\tau}-f_{e, t}^{w} u_{e, t+\tau}
\end{aligned}
$$

where $i$ is the stock of non-participation. We then again assume, like Shimer, that the labor force is constant in the month between CPS interviews. It should be noted that this has the implication that the non-participation stock is also constant between months. Since the unemployment system implicit in the above is a closed one (all flows among unemployment, employment, and non-participation originate from one of these three 
categories), the population (the sum of unemployment, employment, and nonparticipation) is implicitly constant.

Given this, equation (A.4) is just a non-linear system, which can be solved using conventional programs such as MatLab. 
Figure 0: Unemployment Rate and Recessionary Unemployment Dates Used

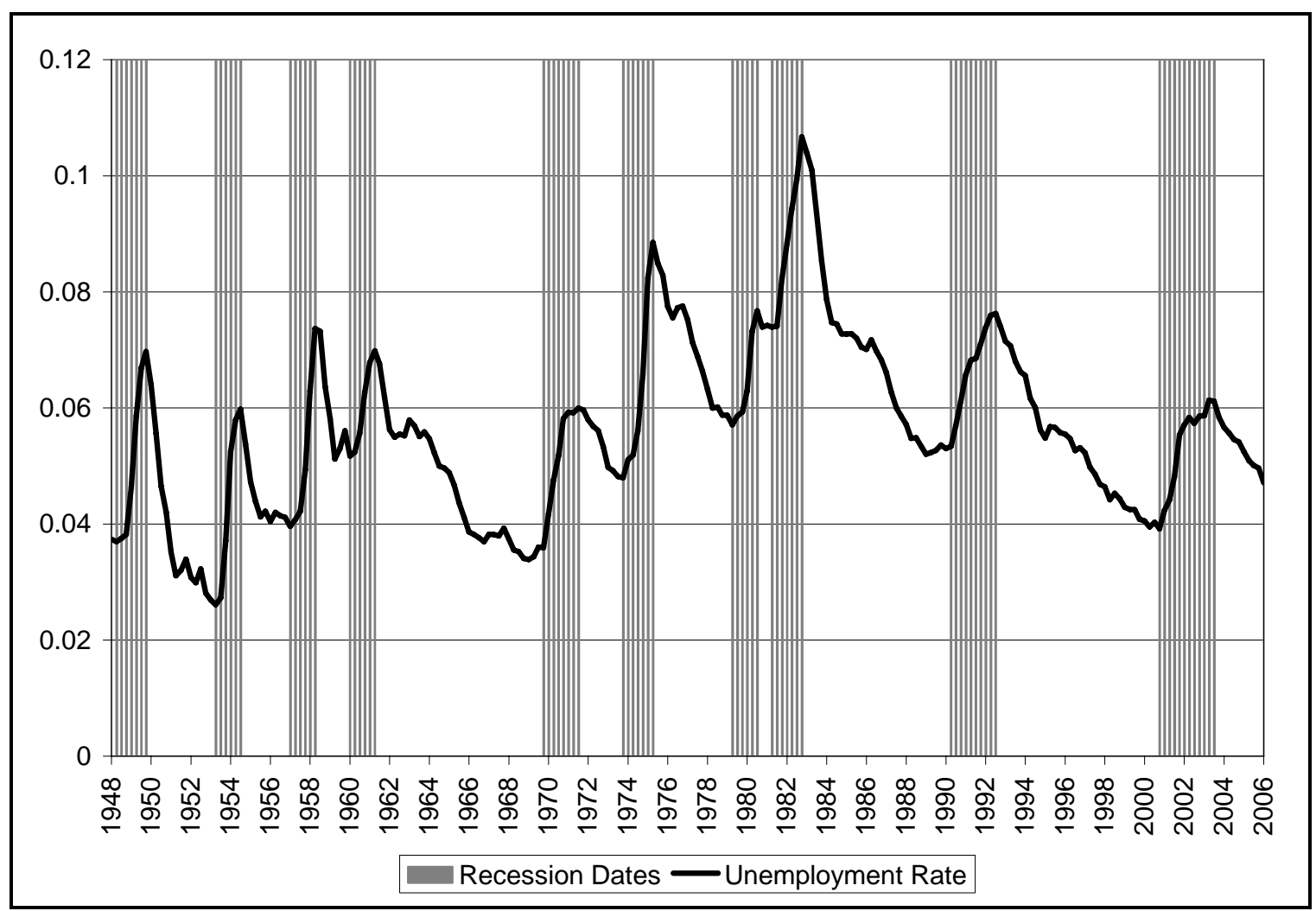


Figure 1: Replication of Shimer's Figure 1

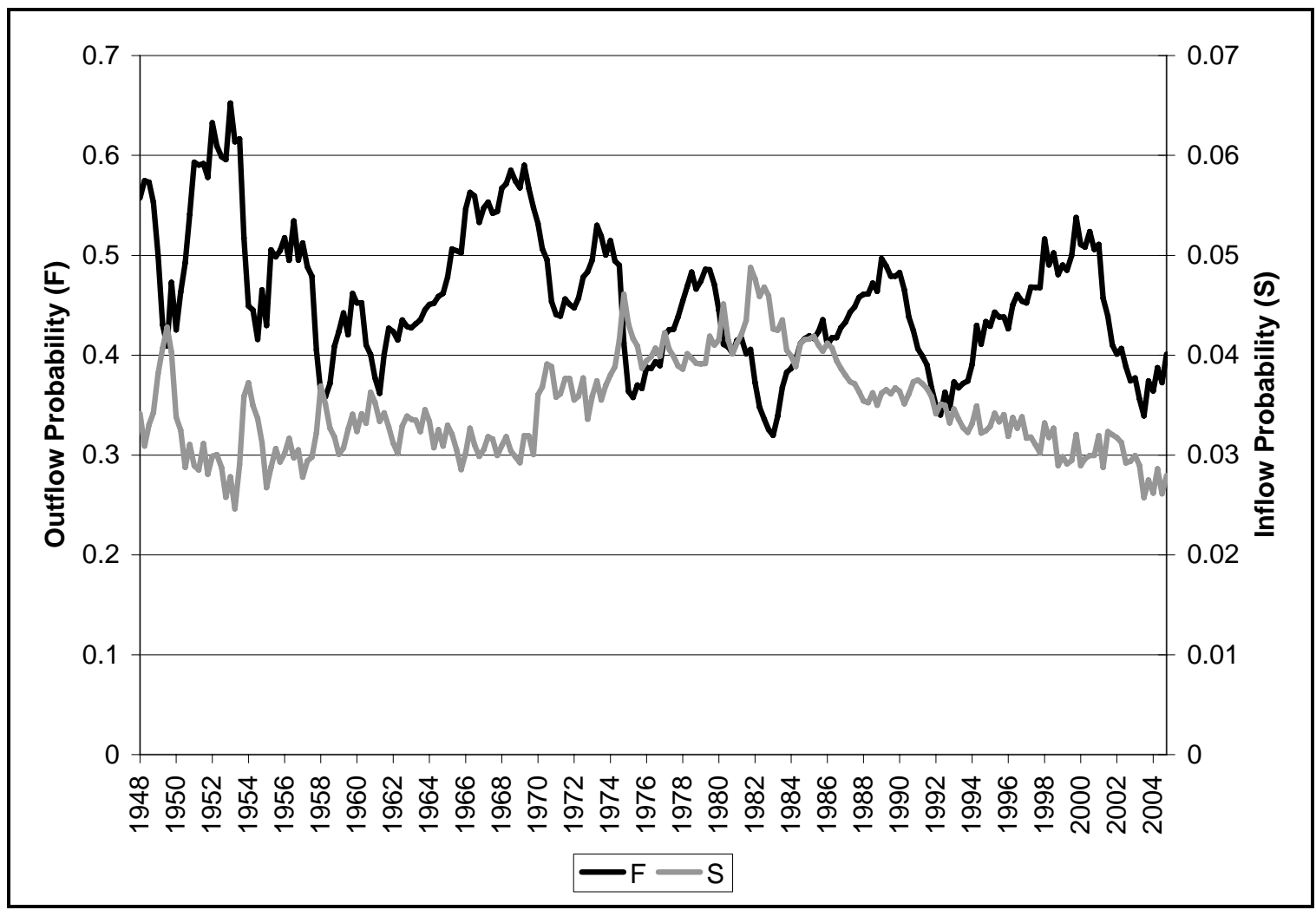


Figure 2: Log Inflow and Outflow Hazard Rates Using Replication of Shimer's Data

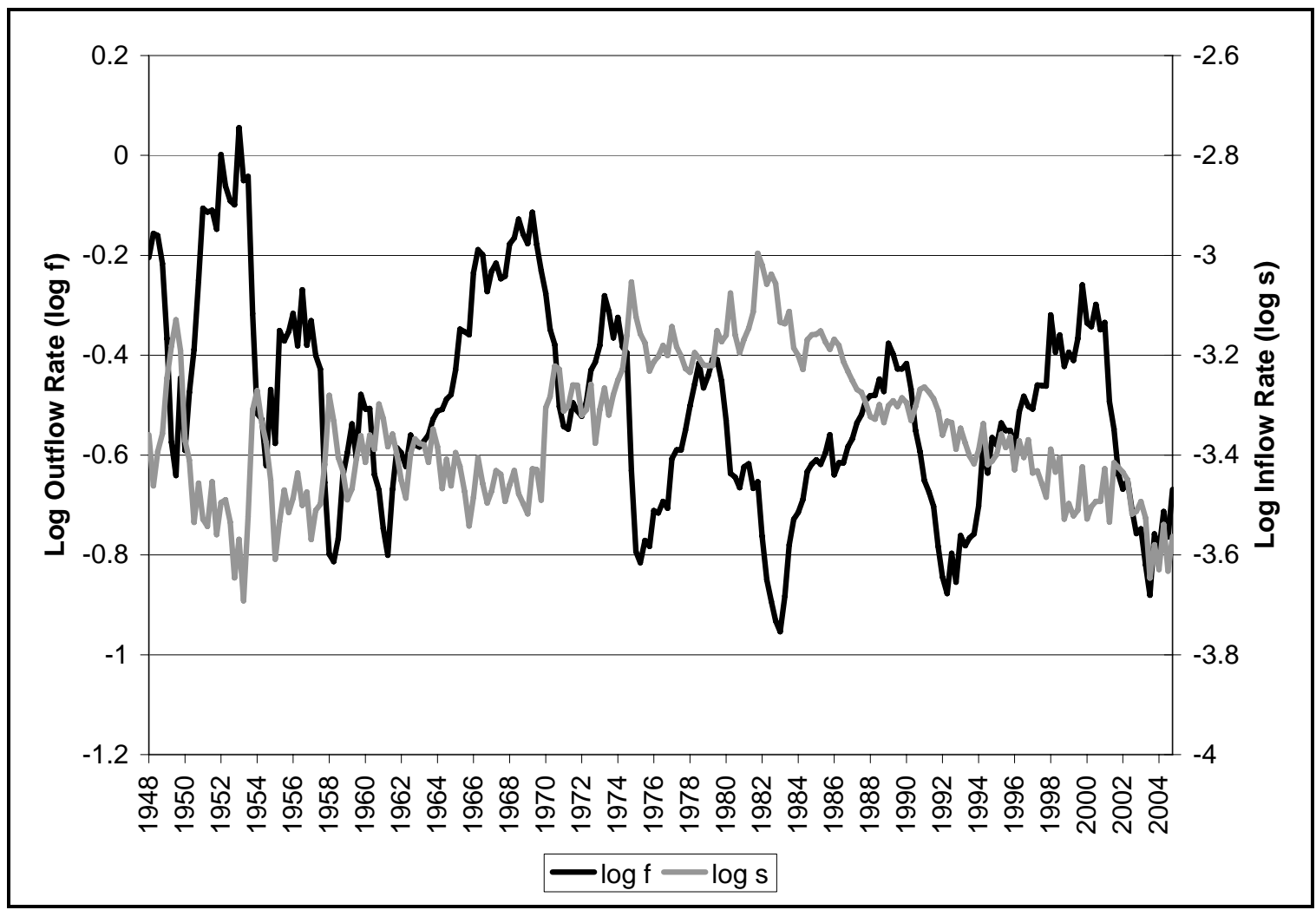


Figure 3: Decomposition of Increases in Log Unemployment by Recession, 1948-2004
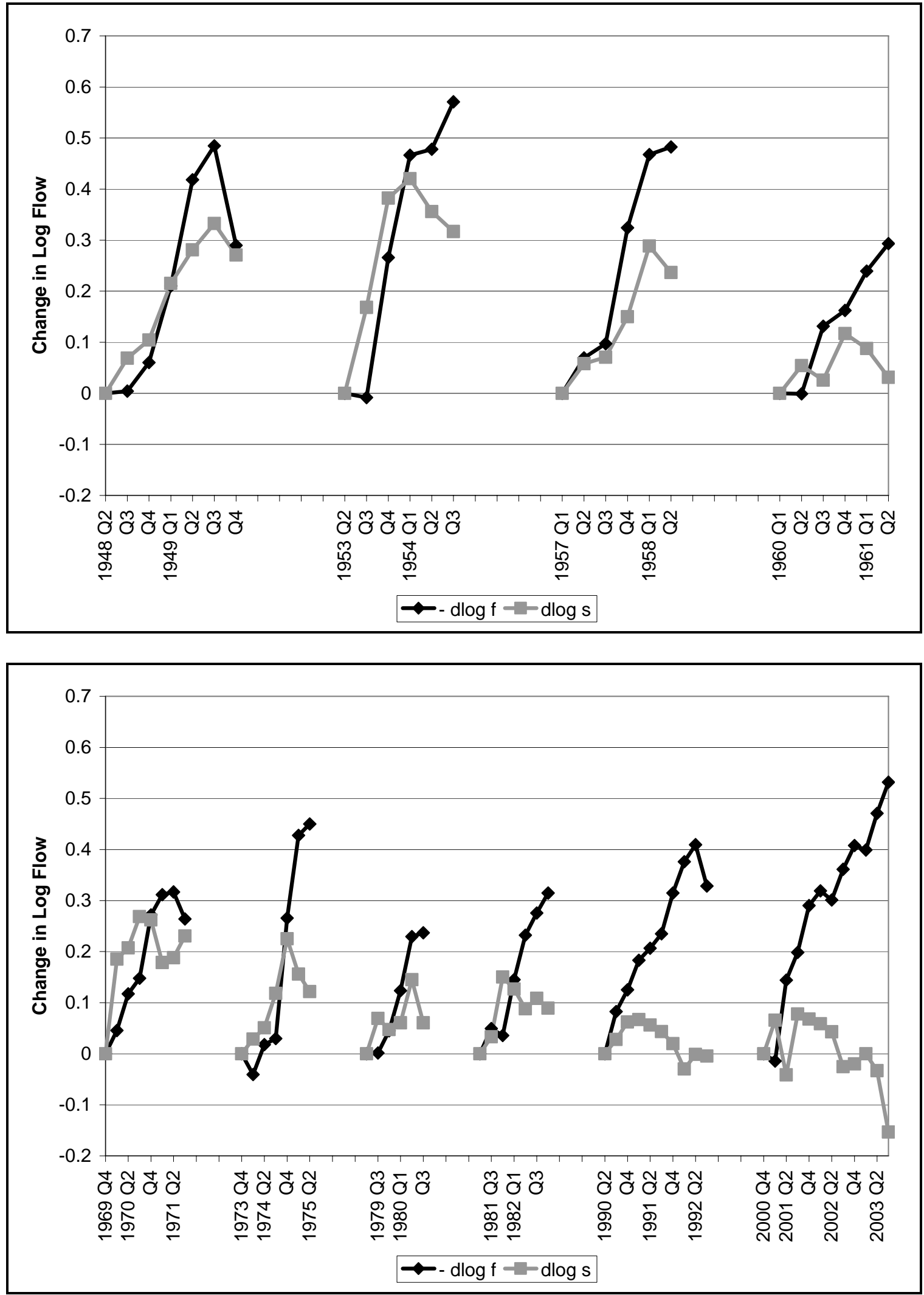
Figure 4: Month-by-Month Ratio of Short-Term Share of Unemployment in Incoming

\section{Rotation Groups to Full Sample}

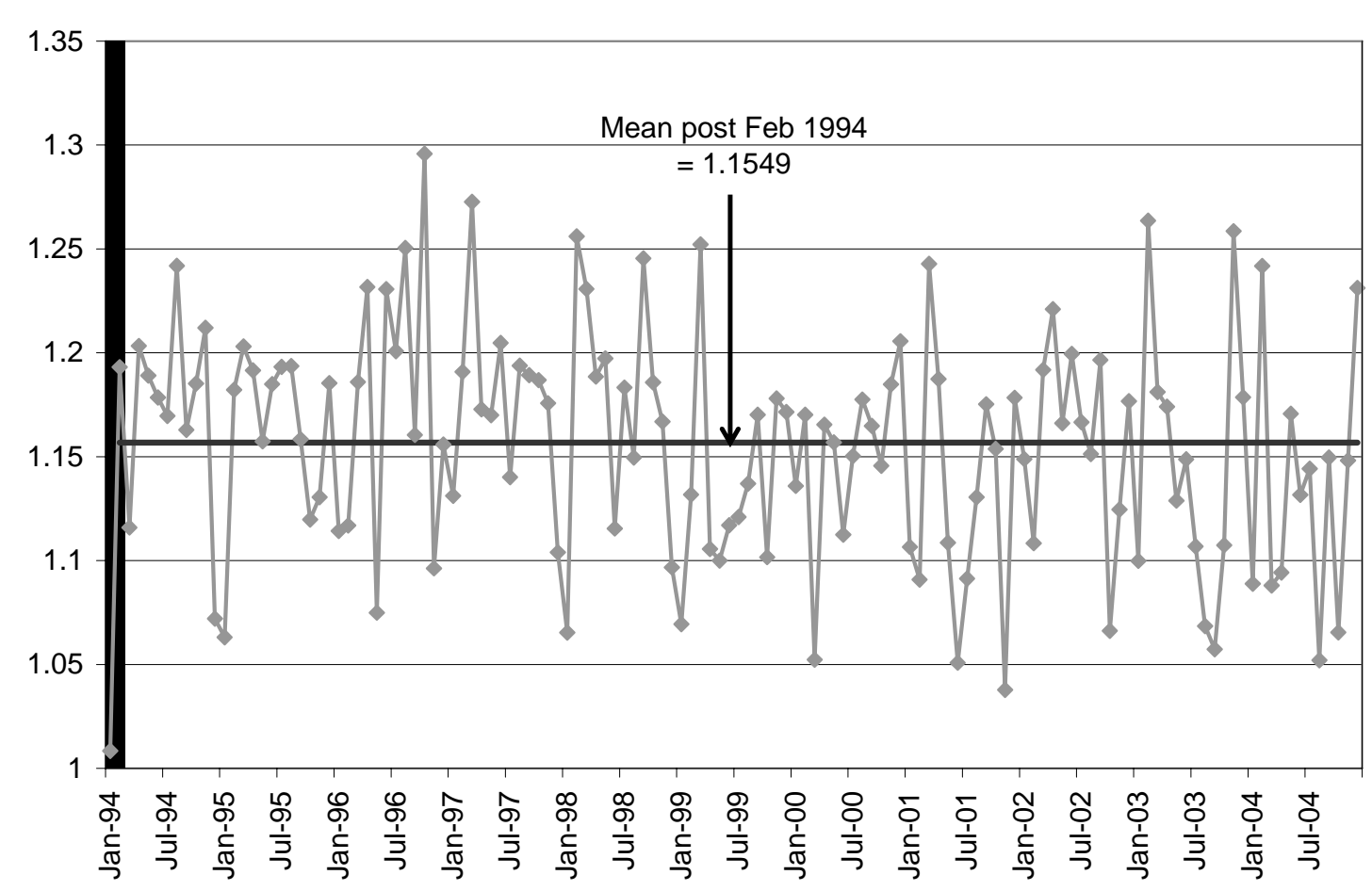

Redesign $\backsim$ IRG/Full Sample Short Term Share of Unemployment — Mean post Feb 1994 
Figure 5: Effect of Our Alternative Redesign Correction on the 2000-2001 Recession

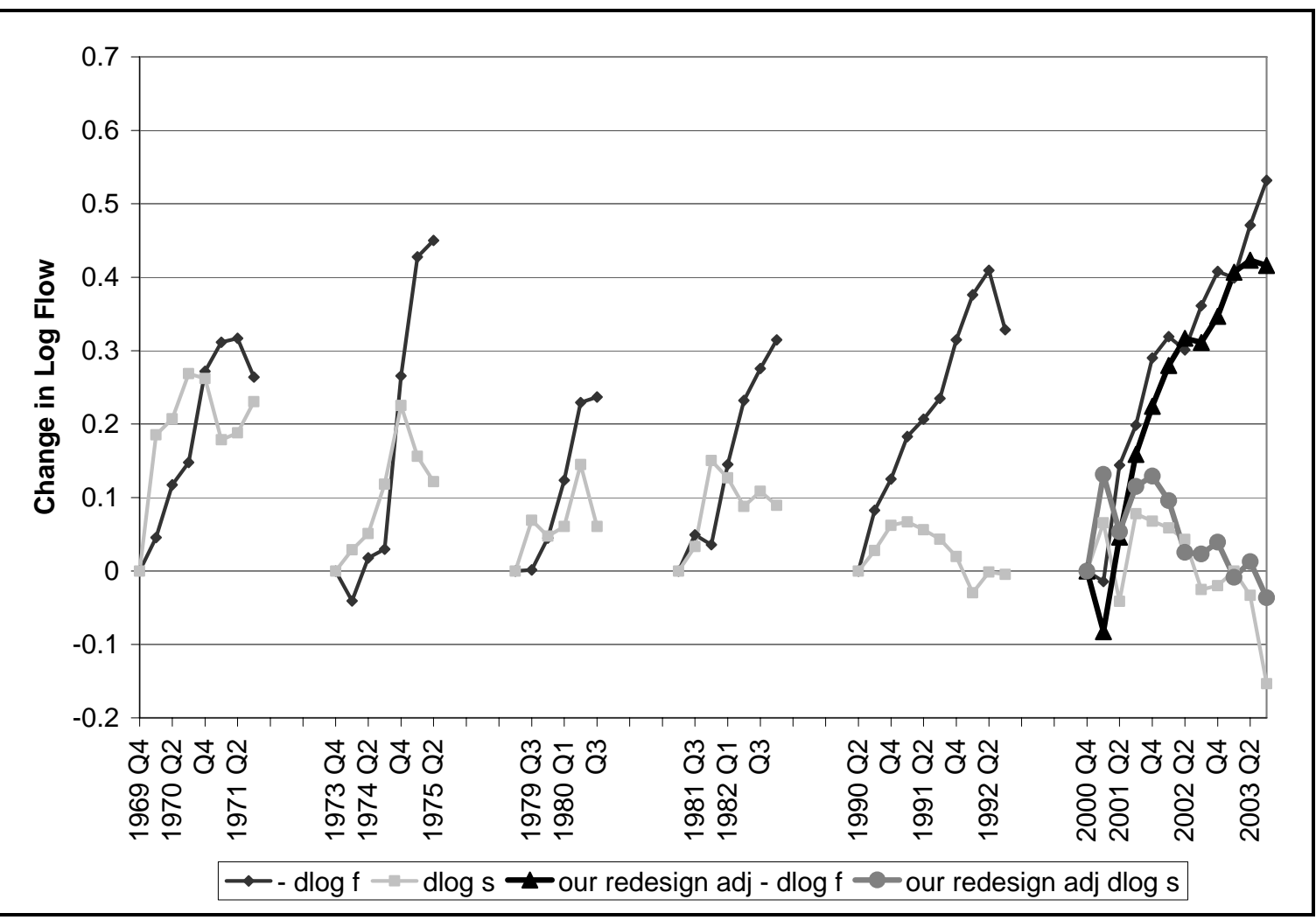


Figure 6: Effects of Different Aggregation Bias Corrections on Measured Log Inflow Rates

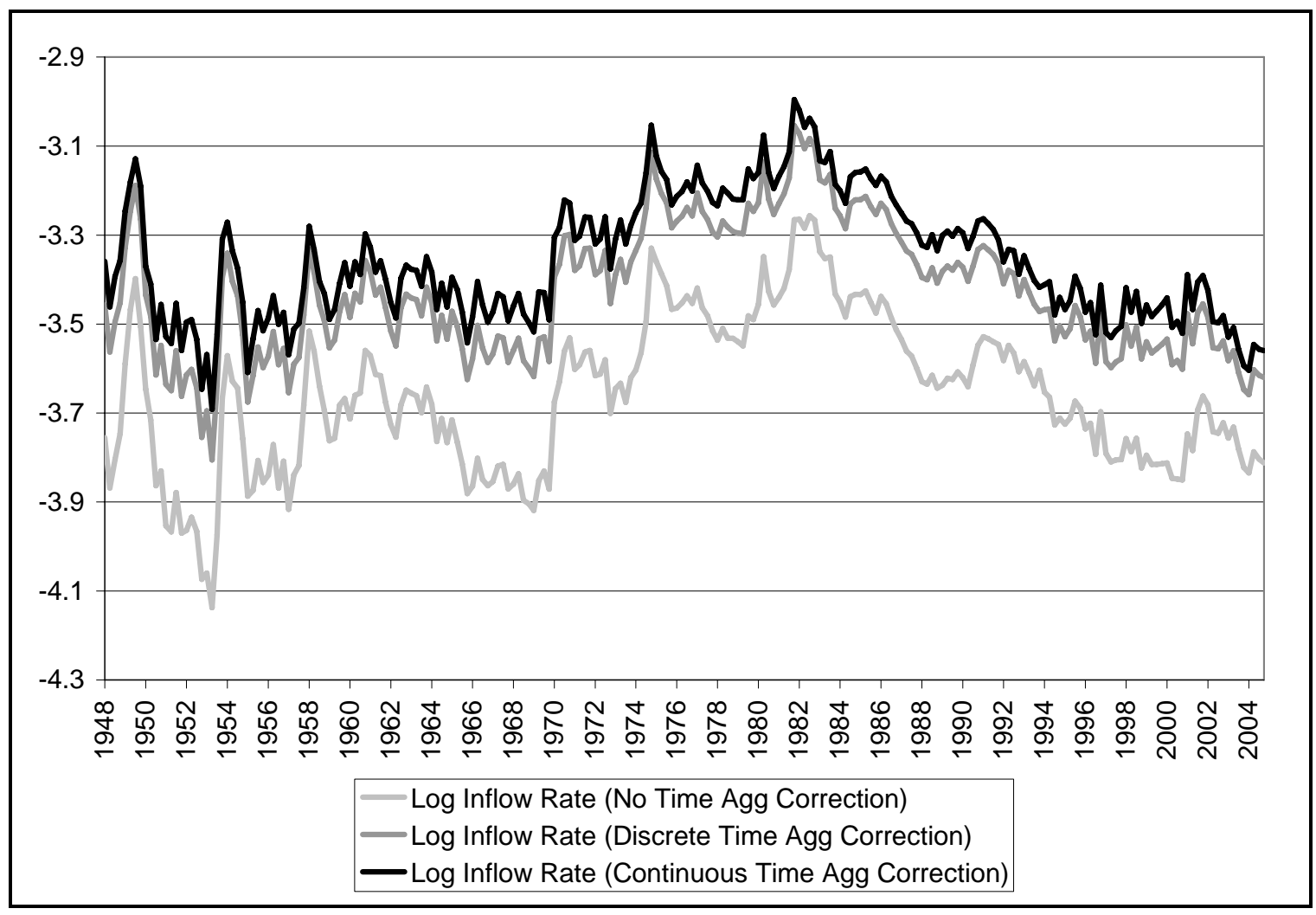


Figure 7: Effects of Aggregation Bias Corrections on Decomposition
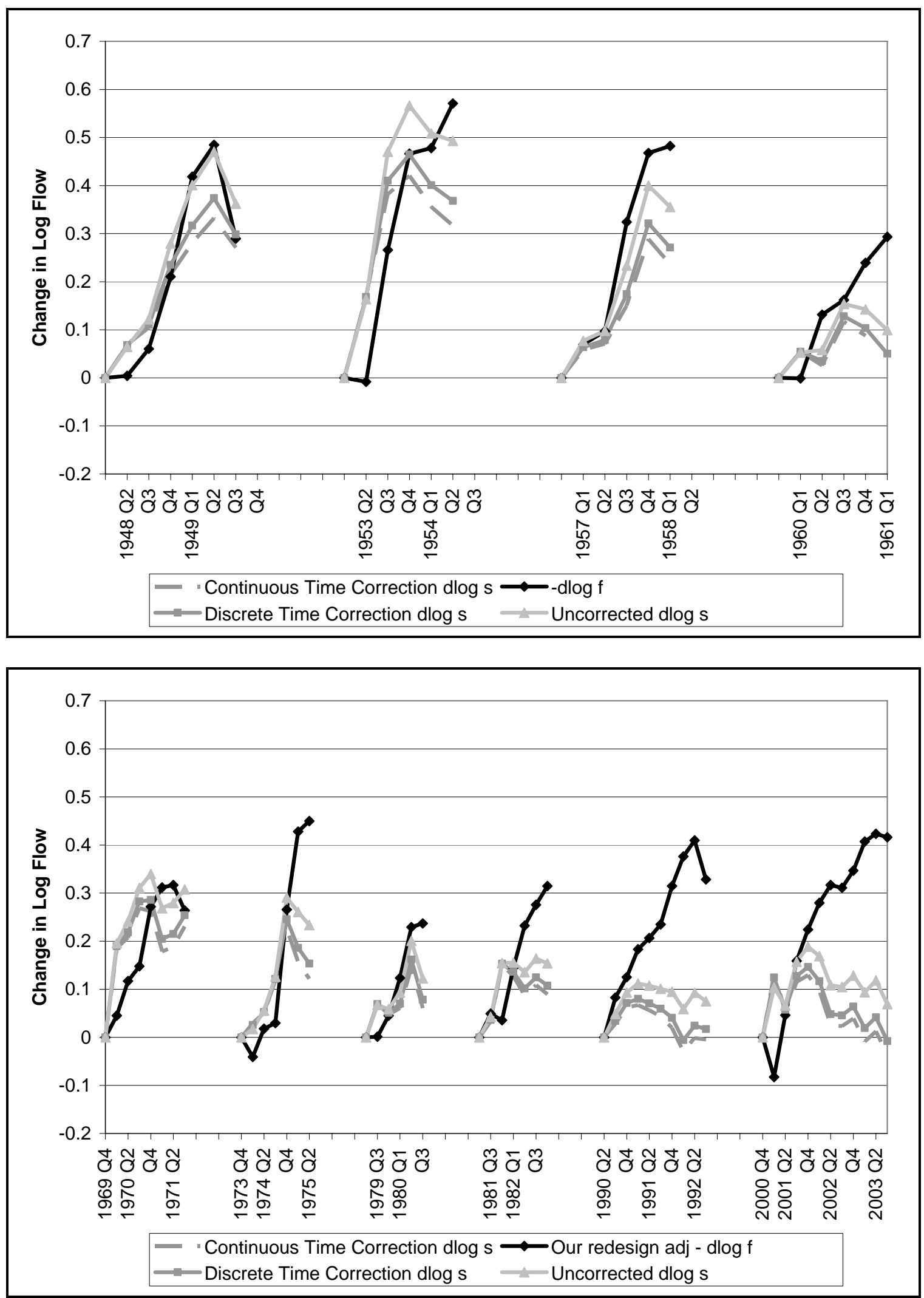
Figure 8: Log Inflow Rates by Reason for Unemployment

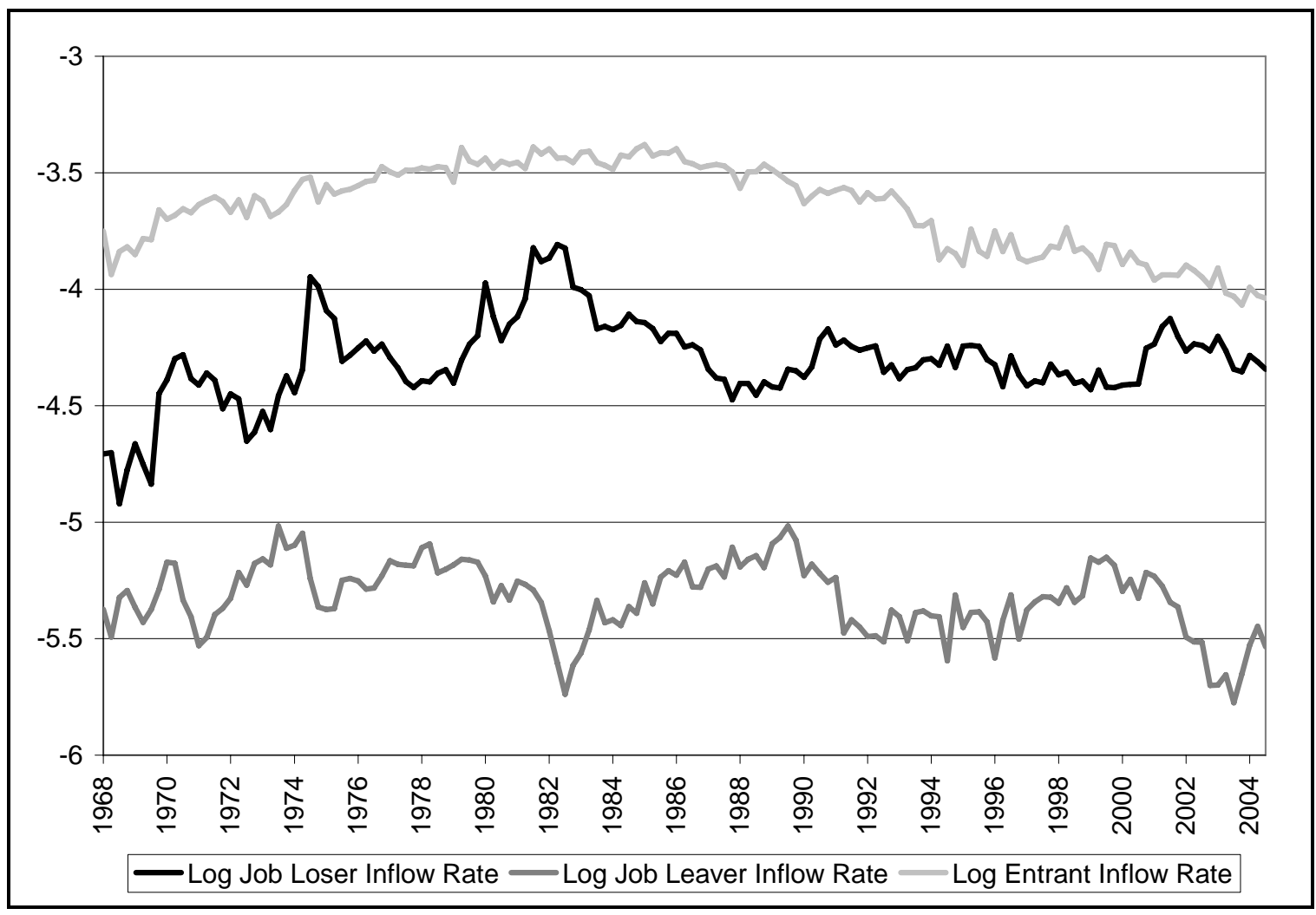


Figure 9: Log Outflow Rates by Reason for Unemployment

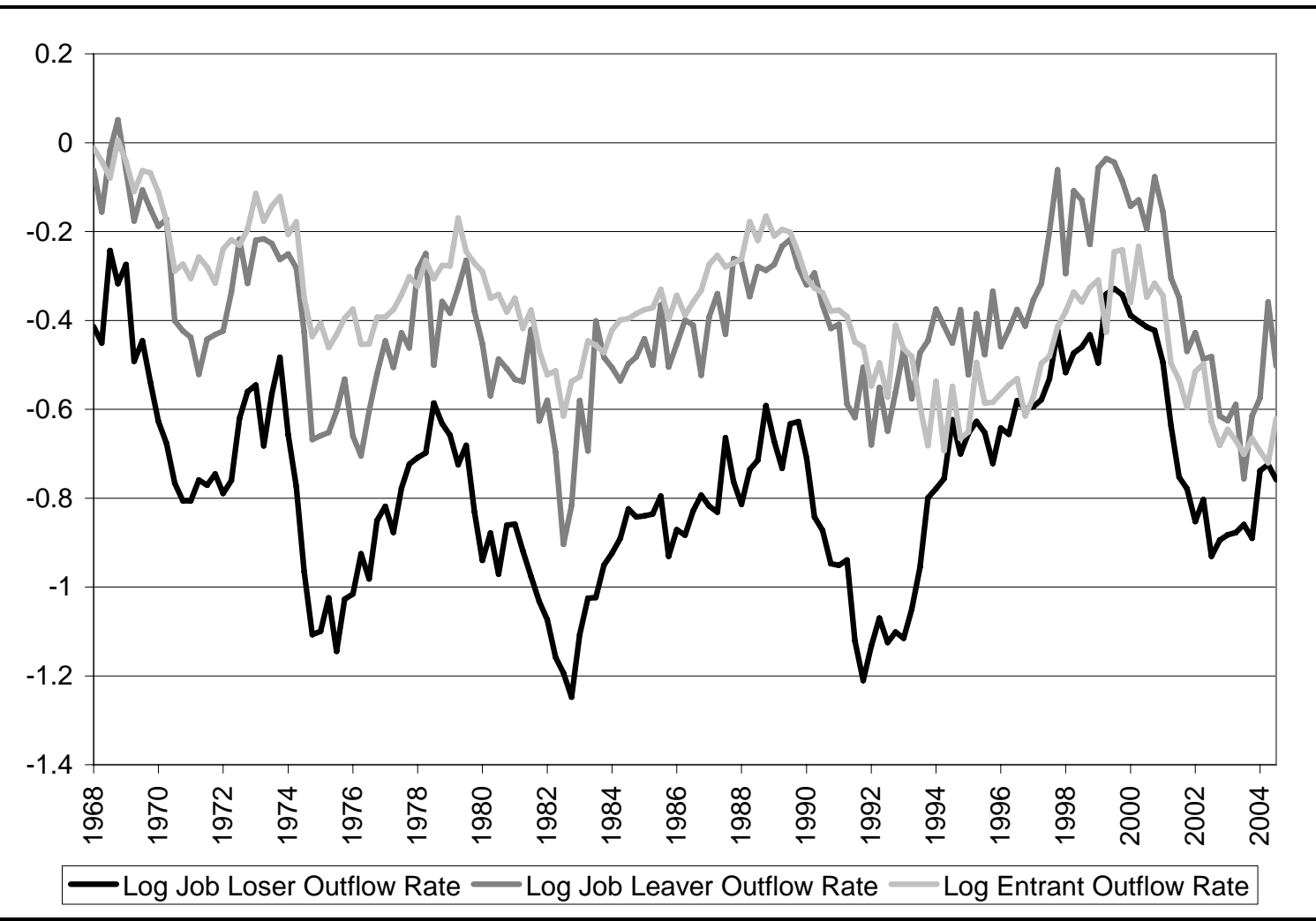


Figure 10: Logs of Employment, Non-Participation, and Unemployment as Fractions of the Labor Force

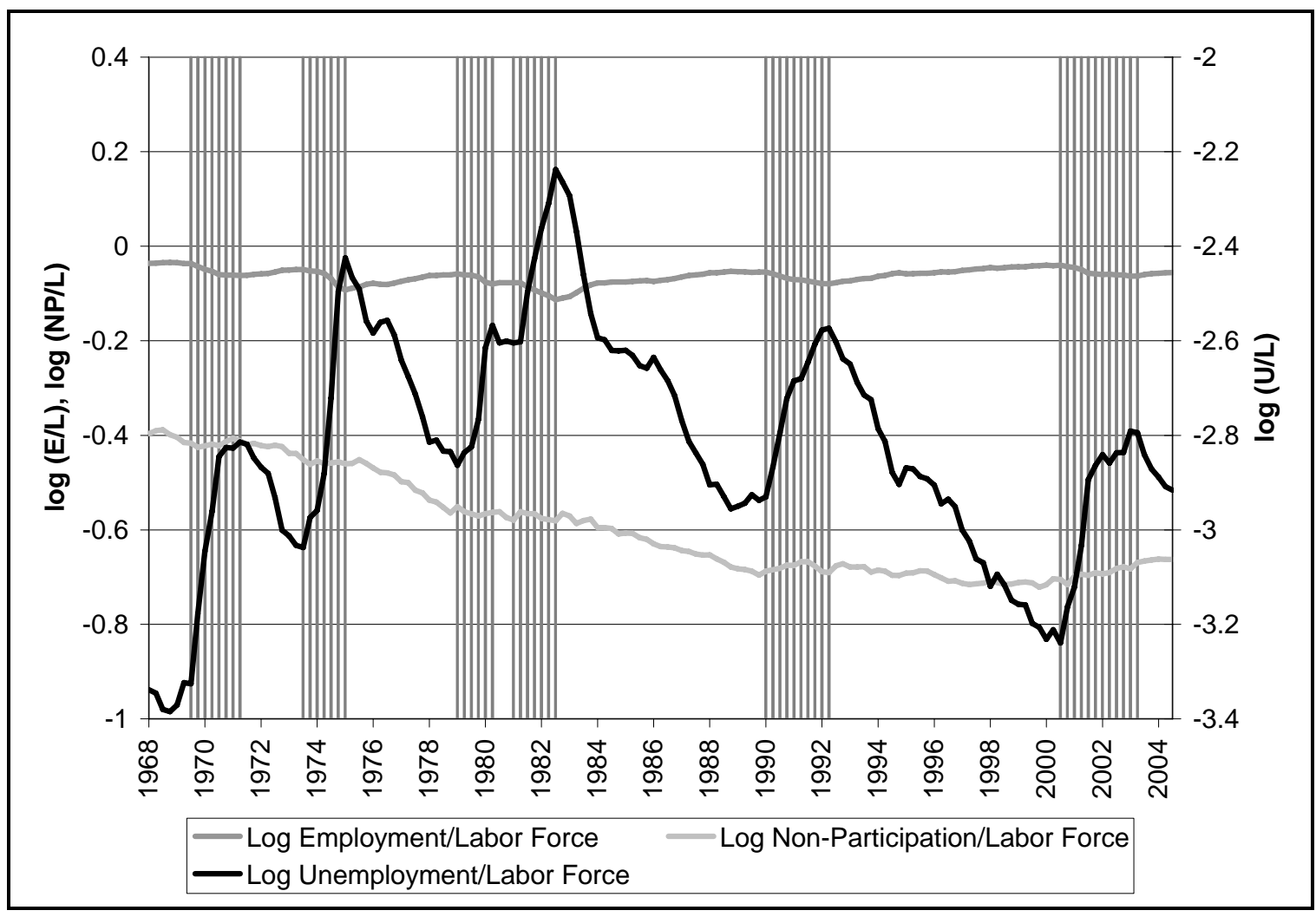


Figure 11: Decomposition of Increase in Unemployment into Effects of Flows by Reason for Unemployment

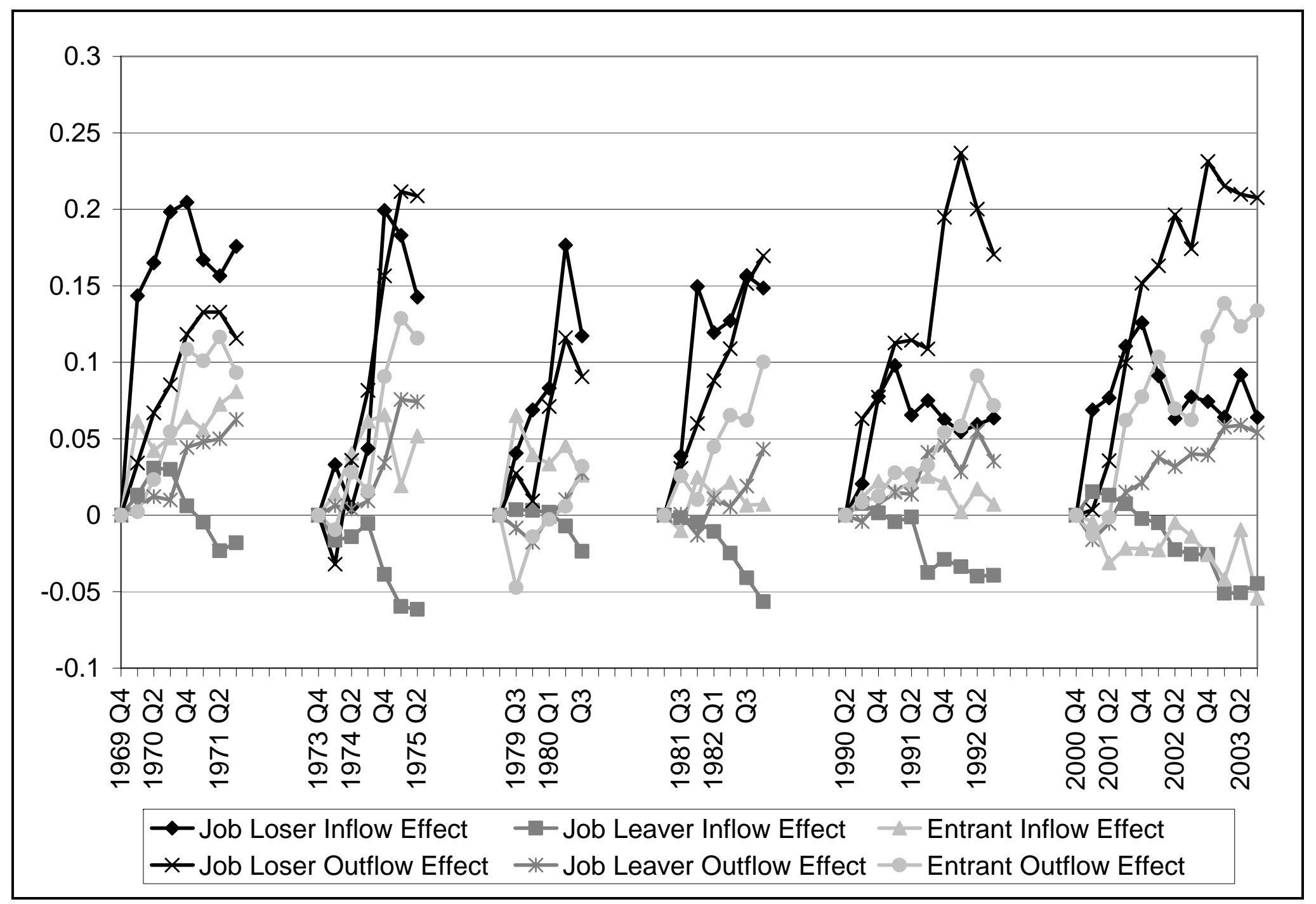


Figure 12: Level of Monthly Outflow from Unemployment (Quarterly Average)

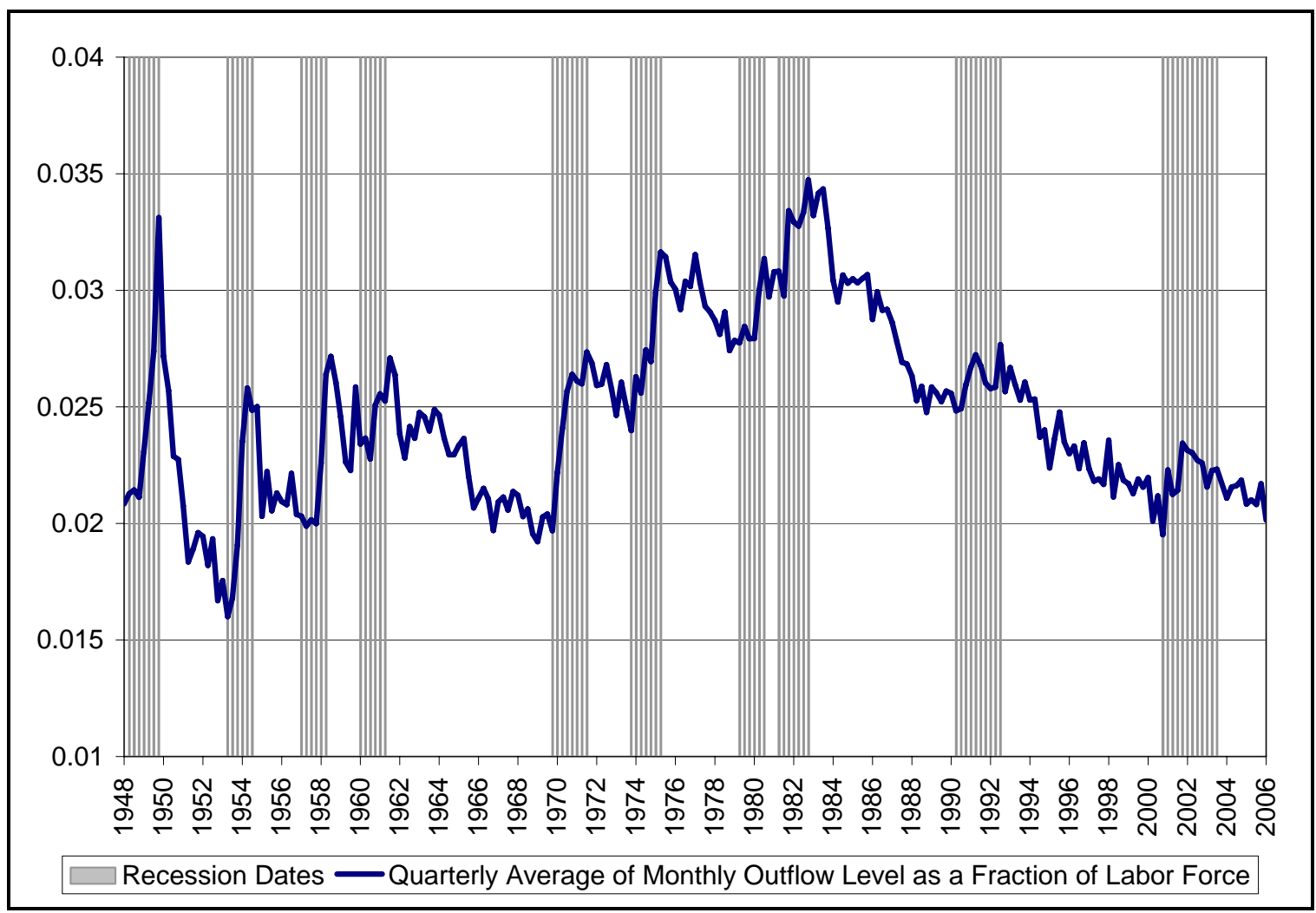




\section{$\underline{\text { References }}$}

Abraham, Katharine G. and Robert Shimer, "Changes in Unemployment Duration and Labor-Force Attachment," in Alan B. Krueger and Robert M. Solow, eds., The Roaring Nineties: Can Full Employment Be Sustained? New York: Russell Sage Foundation and Century Foundation Press, 2001: 367-420.

Akerlof, George A., Andrew K. Rose, and Janet L. Yellen, "Job Switching and Job Satisfaction in the U.S. Labor Market," Brookings Papers on Economic Activity, 1988(2): 495-582.

Anderson, Patricia M. and Bruce D. Meyer, "The Extent and Consequences of Job Turnover," Brookings Papers on Economic Activity: Microeconomics, 1994: 177-236.

Baker, Michael, "Unemployment Duration: Compositional Effects and Cyclical Variability," American Economic Review, March 1992, 82(1): 313-21.

Barkume, Anthony J. and Francis W. Horvath, "Using Gross Flows to Explore Movements in the Labor Force," Monthly Labor Review, April 1995, 118(4): 28-35.

Barth, Peter S., "A Time Series Analysis of Layoff Rates," Journal of Human Resources, Fall 1971, 6(4): 448-65.

Blanchard, Olivier Jean and Peter Diamond, "The Cyclical Behavior of the Gross Flows of U.S. Workers," Brookings Papers on Economic Activity, 1990(2): 85-143.

Blanchard, Olivier and Jordi Gali, "A New Keynesian Model with Unemployment," mimeo, MIT and CREI, 2006.

Bleakley, Hoyt, Ann E. Ferris, and Jeffrey C. Fuhrer, "New Data on Worker Flows during Business Cycles," New England Economic Review, July-August 1999: 49-76.

Cole, Harold L. and Richard Rogerson, "Can the Mortensen-Pissarides Matching Model Match the Business-Cycle Facts?" International Economic Review, November 1999, 40(4): 933-59.

Darby, Michael R., John C. Haltiwanger, and Mark W. Plant, “The Ins and Outs of Unemployment: The Ins Win," Working Paper No. 1997, National Bureau of Economic Research, 1986.

Davis, Steven J., "Job Loss, Job Finding, and Unemployment in the U.S. Economy over the Past Fifty Years: Comment," in Mark Gertler and Kenneth Rogoff, eds., NBER Macroeconomics Annual 2005, Cambridge, MA: MIT Press, 2006: 139-57 
Davis, Steven J., R. Jason Faberman, and John Haltiwanger, "The Flow Approach to Labor Markets: New Data Sources and Micro-Macro Links," Journal of Economic Perspectives, Summer 2006, 20(3): 3-26.

Fujita, Shigeru and Garey Ramey, "The Cyclicality of Job Loss and Hiring," mimeo, Federal Reserve Bank of Philadelphia and University of California at San Diego, 2006.

Gertler, Mark and Antonella Trigari, "Unemployment Fluctuations with Staggered Nash Wage Bargaining," Working Paper No. 12498, National Bureau of Economic Research, 2006.

Hall, Robert E., "Examining Alternative Macroeconomic Theories: Comment," Brookings Papers on Economic Activity, 1988(1): 261-64.

Hall, Robert E., "Employment Fluctuations with Equilibrium Wage Stickiness," American Economic Review, March 2005a, 95(1): 50-65.

Hall, Robert E., "Employment Efficiency and Sticky Wages: Evidence from Flows in the Labor Market," Review of Economics and Statistics, August 2005b, 87(3): 397-407.

Hall, Robert E., "Job Loss, Job Finding, and Unemployment in the U.S. Economy over the Past Fifty Years," in Mark Gertler and Kenneth Rogoff, eds., NBER Macroeconomics Annual 2005, Cambridge, MA: MIT Press, 2006: 101-37.

Kennan, John, "Job Loss, Job Finding, and Unemployment in the U.S. Economy over the Past Fifty Years: Comment," in Mark Gertler and Kenneth Rogoff, eds., NBER Macroeconomics Annual 2005, Cambridge, MA: MIT Press, 2006: 159-64.

Marston, Stephen T., "Employment Instability and High Unemployment Rates," Brookings Papers on Economic Activity, 1976(1): 169-203.

Menzio, Guido and Espen R. Moen, "Incomplete Self-Enforcing Labor Contracts," mimeo, University of Pennsylvania and Norwegian School of Management, 2006.

Mortensen, Dale T. and Christopher A. Pissarides, "Job Creation and Job Destruction in the Theory of Unemployment," Review of Economic Studies, July 1994, 61(3): 397-415.

National Commission on Employment and Unemployment Statistics, Counting the Labor Force, Washington, DC: U.S. Government Printing Office, 1979.

Nicholson, Walter, "A Statistical Model of Exhaustion of Unemployment Insurance Benefits," Journal of Human Resources, Winter 1981, 16(1): 117-28.

Perry, George L., "Unemployment Flows in the U.S. Labor Market," Brookings Papers on Economic Activity, 1972(2): 245-78. 
Pissarides, Christopher A., "Short-Run Equilibrium Dynamics of Unemployment, Vacancies, and Real Wages," American Economic Review, September 1985, 75(4): 67690.

Polivka, Anne E. and Stephen M. Miller, "The CPS after the Redesign: Refocusing the Economic Lens," in John Haltiwanger, Marilyn E. Manser, and Robert Topel, eds., Labor Statistics Measurement Issues, Chicago: University of Chicago Press, 1998: 249-86.

Rotemberg, Julio J., "Cyclical Wages in a Search-and-Bargaining Model with Large Firms," Working Paper No. 12415, National Bureau of Economic Research, 2006.

Shimer, Robert, "Reassessing the Ins and Outs of Unemployment," mimeo, University of Chicago, 2005a.

Shimer, Robert, "The Cyclicality of Hires, Separations, and Job-to-Job Transitions," Federal Reserve Bank of St. Louis Review, July-August 2005b, 87(4): 493-507.

Shimer, Robert, "Discussion of Robert E. Hall's REStat Lecture 'Employment Efficiency and Sticky Wages: Evidence from Flows in the Labor Market," Review of Economics and Statistics, August 2005c, 87(3): 408-10.

Sider, Hal, "Unemployment Duration and Incidence: 1968-82," American Economic Review, June 1985, 75(3): 461-72.

Slichter, Sumner H., The Turnover of Factory Labor, New York: D. Appleton and Company, 1919.

Woytinsky, W. S., Three Aspects of Labor Dynamics, Washington, DC: Social Science Research Council, 1942.

Yashiv, Eran, “U.S. Labor Market Dynamics Revisited,” mimeo, Tel Aviv University, 2006. 